IZA DP No. 721

Do Oppositional Identities Reduce

Employment for Ethnic Minorities?

Harminder Battu

McDonald Mwale

Yyes Zenou

February 2003 


\title{
Do Oppositional Identities Reduce Employment for Ethnic Minorities?
}

\author{
Harminder Battu \\ University of Aberdeen \\ McDonald Mwale \\ University of Aberdeen \\ Yves Zenou \\ University of Southampton, \\ GAINS, CEPR and IZA Bonn
}

\author{
Discussion Paper No. 721 \\ February 2003
}

\author{
IZA \\ P.O. Box 7240 \\ D-53072 Bonn \\ Germany \\ Tel.: +49-228-3894-0 \\ Fax: +49-228-3894-210 \\ Email: iza@iza.org
}

This Discussion Paper is issued within the framework of IZA's research area Mobility and Flexibility of Labor. Any opinions expressed here are those of the author(s) and not those of the institute. Research disseminated by IZA may include views on policy, but the institute itself takes no institutional policy positions.

The Institute for the Study of Labor (IZA) in Bonn is a local and virtual international research center and a place of communication between science, politics and business. IZA is an independent, nonprofit limited liability company (Gesellschaft mit beschränkter Haftung) supported by the Deutsche Post AG. The center is associated with the University of Bonn and offers a stimulating research environment through its research networks, research support, and visitors and doctoral programs. IZA engages in (i) original and internationally competitive research in all fields of labor economics, (ii) development of policy concepts, and (iii) dissemination of research results and concepts to the interested public. The current research program deals with (1) mobility and flexibility of labor, (2) internationalization of labor markets, (3) welfare state and labor market, (4) labor markets in transition countries, (5) the future of labor, (6) evaluation of labor market policies and projects and (7) general labor economics.

IZA Discussion Papers often represent preliminary work and are circulated to encourage discussion. Citation of such a paper should account for its provisional character. A revised version may be available on the IZA website (www.iza.org) or directly from the author. 
IZA Discussion Paper No. 721

February 2003

\section{ABSTRACT}

\section{Do Oppositional Identities Reduce Employment for Ethnic Minorities?*}

We develop a model in which non-white individuals are defined with respect to their social environment (family, friends, neighbors) and their attachments to their culture of origin (religion, language), and in which jobs are mainly found through social networks. We found that, depending on how strong they are linked to their culture of origin, non-whites choose to adopt "oppositional" identities since some individuals may identify with the dominant culture (status seekers) and others may reject that culture (conformists), even if it implies adverse labor market outcomes. We then test this model using a unique data set that contains extensive information on various issues surrounding ethnic identity and preferences in Britain. We find considerable heterogeneity in the ethnic population of Britain in terms of ethnic preferences. One group, namely the African-Asians, stand out in having preferences that accord with the notion of them being status seekers. Such preferences are closely tied to a range of assimilation variables and those non-whites who have preferences that accord with being a conformist do experience an employment penalty.

JEL Classification: J15

Keywords: $\quad$ social networks, white's norm, ethnic minorities

Corresponding author:

Yves Zenou

Department of Economics

University of Southampton

S017 1BJ

Southampton

U.K.

Tel.: +442380593264

Fax: +4423805938 58

Email: yz@soton.ac.uk

\footnotetext{
*We would like to thank Thibaud Vergé for helpful comments.
} 


\section{Introduction}

During the spring and early summer of 2001 there were a series of violent disturbances in various cities and towns in England. As a consequence a number of local and national enquiries were formed to investigate the causes of these disturbances. Though a range of potential explanations were proposed two received considerable attention both in political circles but also in the media. First, the lack of a shared civic identity to bring together diverse communities. Second, increasing segregation of communities on economic, geographic, racial and cultural lines even where this reflected individual preferences. ${ }^{1}$ The attention paid to these two factors is relatively novel in the UK and does represent a departure from the long-standing debate in the UK which has tended to emphasize racial discrimination as the key force in driving ethnic disadvantage (CRE, 2002).

Recent research, however, has started to pay much closer attention to these types of issues. One theme that has emerged is that some individuals in ethnic groups may "choose" to adopt what are termed "oppositional" identities. Where a community or group is socially excluded from a dominant group, some individuals of that group may identify with the dominant culture and others may reject that culture (Akerlof and Kranton, 2000). ${ }^{2}$ This may occur even if the latter groups preferences involves a lower economic return. From the standpoint of those who choose not to take a rejectionist stance the rejectionists are making poor economic decisions; they are engaging in what might be termed self-destructive behavior. Such preferences may stem from a lack of economic opportunity, discrimination or it may stem from a desire to display greater racial or religious solidarity.

There are some indications of oppositional preferences within the United States. For African Americans, Ihlanfeldt and Scafidi (2002) evoke a wish to share culture, prejudice against whites, or expectations of unfavorable treatment by whites against non-whites in white neighborhoods. One could also think of the advantages members of a minority group can derive from locating close to one another, thereby improving their access to 'ethnic goods' such as food, education or religious service, not to mention the ability to socially interact in their own language (Akerlof and Kranton, 2000). Other studies for the US have found that African American students in poor areas may be ambivalent about learning standard English, where this may be regarded as "acting white" and adopting mainstream identities (Wilson, 1987, Delpit, 1995, Ogbu, 1997). Interestingly, a key result of the sociological literature is that members of the same minority group may exhibit different levels of ethnic preferences. This is confirmed by a 1992 study of non-whites in the Detroit Metropolitan Area (Bledsoe et al., 1995) which shows that non-whites who live in

\footnotetext{
${ }^{1}$ For further details on these reports see Building Cohesive Communities (2001).

${ }^{2}$ An alternative explanation revolves around qualifications: skilled minorities could benefit more from integration than unskilled minorities (Cutler and Glaeser, 1997).
} 
predominantly non-white neighborhoods display greater solidarity than those who live in mixed neighborhoods.

In the economics literature there is no direct evidence on what drives such behavior and on the implications of such behavior for labor market outcomes. Blackaby et al. (1997) for the UK have argued that the labor market disadvantage of ethnic groups may stem from what they describe as "the cultural outlook of the minority group itself". They go further and argue that some groups may have "a taste for isolation" which limits their economic opportunities and raises their unemployment rates. The authors do not, however, conduct any formal empirical analysis to gauge the importance of these effects. Similarly Berthoud (2000) acknowledges the importance of identity related factors in his discussion of the alienation of certain groups, which he argues is a consequence and a reinforcing cause of their exclusion from employment. Again, there is no attempt to get to grips with these issues at an empirical level. Brown (2000) makes a similar argument when he argues that quantitative work has been constrained by a general failure to collect "cultural" information. There is a tendency then to use ethnic group variables as a catch-all measure for cultural differences.

In this paper, we first develop a model in which non-white individuals are defined with respect to their social environment (family, friends, neighbors) and their attachments to their culture of origin (religion, language), and in which jobs are mainly found through social networks. Non-whites must decide to totally or partially adopt the white's culture or to reject it by anticipating the implications of this choice on their labor market outcomes. Interacting with whites is beneficial because non-white workers may then benefit from the high quality of whites' social networks since the latter are not discriminated against. We found that, depending on how strong they are linked to their culture of origin, non-whites choose to adopt "oppositional" identities since some of them may identify with the dominant culture and others may reject that culture. We found in particular that some of the non-whites will totally reject the white's culture even though they know that it will sharply decrease their chance of being employed. ${ }^{3}$

We then undertake a direct empirical investigation of the relationship between an oppositional identity and employment in the labor market. We have at our disposal a unique data set for Britain, which deliberately over-samples ethnic groups and contains extensive information on various issues surrounding ethnic identity and preferences. In particular, we examine three issues. First, how can we measure an oppositional identity? Second, what factors might lead some to adopt or possess such an oppositional identity? Third, what are the consequences for employment and is

\footnotetext{
${ }^{3}$ Few theoretical models have investigated the link between ethnic preferences and labor market outcomes. Akerlof (1997) discusses informally a model that has these features whereas Selod and Zenou (2002) essentially focuses on the urban consequences (i.e. ghettos) of ethnic preferences.
} 
there an employment penalty for those who possess an oppositional identity? We find considerable heterogeneity in the ethnic population of Britain in terms of ethnic preferences. One group, namely the African-Asians, stand out in having preferences that accord with a conceptualization of them as status seekers (they are least likely to be oppositional in their preferences and more likely to accept mainstream values). Such preferences are closely tied to a range of assimilation variables and those nonwhites who have oppositional preferences (the conformists) do in accordance with our theoretical predictions receive an employment penalty.

The remainder of the paper has the following structure. In the next section, we develop the theoretical model. In section 3, our data set is described and we give some descriptive statistics. Section 4 deals with the measurement of ethnic

preferences. Section 5 presents the empirical results. The final section offers a summary and suggests some further avenues of research.

\section{The theoretical model}

In this section, we would like to derive a simple model showing that ethnic preferences (the desire or reluctance to interact with individuals of other ethnic groups) can have strong implications in the labor market. There are two stages. In the first one, non-white individuals decide to adopt the white's norm or not anticipating the implications of this choice on their labor market outcomes. This is the second stage. Before describing each stage, we will first expose the utilities of the workers and how workers obtain a job.

\subsection{Ethnic preferences and utilities}

We assume that there are two types of individuals: non-whites and whites. We locate these individuals in a line (the social space) of length is 1. For simplicity, the white's norm is normalized to zero and all other workers (non-whites) define themselves with respect to this norm.

As we will see below, non-white workers optimally choose their "location" $0 \leq$ $x \leq 1$ in the social space. In this line, there are two extreme locations: $x=0$ means to totally adopt the white's norm and thus to totally reject the norm of the ethnic group the worker belongs to whereas $x=1$ implies the contrary (to totally reject the white's norm and thus to totally adopt the norm of the ethnic group the worker belongs to). Any location's choice of $0<x<1$ leads to a behavior which is in between these two extremes. Thus, the larger $x$ the more distant the worker is from the white's norm and the closer he/she is from his/her own community because the more time one spends with the white community, the less time he/she spends with his/her own community. For example, as we will see in the empirical part of this paper (see Tables 2 and 4), some ethnic minority groups living in Britain do not 
think themselves as British and do not want a close relative to marry a white person. These individuals have clearly chosen be close to 1 in the social space. Those who answer the opposite have chosen to be close to 0 in the social space. There are also indirect ways to distance oneself from the white culture. Some ethnic minority persons think that ethnicity is important in choosing a school (Table 5) and that there should be more than half pupils of the same ethnic group in the school (Table 6 ). This is an indirect way to distant oneself to the white's norm since it makes the interaction with whites more difficult.

In our model, preferences of individuals are not identical. It is convenient to focus on three groups of individuals: whites, denoted by $W$, non-white status-seekers $(B S)$, and non-white conformists $(B C)$. For non-whites, being of type $B S$ or $B C$ defines the "initial conditions" (the family, the local environment, ...) of each individual but not the choice of $x$. Conformists are individuals that are born and educated in a family (and community) that had few contacts with whites and have thus interacted exclusively with individuals from the same community. On the contrary, status-seekers are more assimilated and were raised in a family that was eager to have contacts with whites.

Let us now express the utility functions of workers who are all assumed to be risk neutral. Since whites are located at $x=0$, the utility function of a white worker of employment status $j=U, E$ is given by:

$$
V_{W j}=y_{j}
$$

where $y_{j}$ is the exogenous income of a worker with employment status $j$ ( $y_{E}$ and $y_{U}$ are respectively the wage of the employed and the unemployment benefit, with $\left.y_{E}>y_{U}>0\right)$. The respective utility functions for a status-seeker and a conformist non-white worker of employment status $j=U, E$, and "location" $x$, are given by:

$$
\begin{aligned}
& V_{B S j}(x)=y_{j}-e_{B S} x \\
& V_{B C j}(x)=y_{j}+e_{B C} x
\end{aligned}
$$

with $e_{B S}>0$ and $e_{B C}>0$.

In our formulation, the racial externality incurred by a worker of the non-white community is expressed through the "distance" $x$ in the social space to the white community (i.e. the white's norm). For conformists, it is easy to see that when the distance to the white community increases, utility increases, reflecting the disutility of interracial contacts with white "neighbors". This is the case because some nonwhite workers may not "trust" people from other communities, especially whites, especially when they have been historically discriminated against (see Alesina and La Ferrara, 2002, for an interesting study on trust and racial mixing). To the contrary, 
the utility of status-seekers increases with proximity to the white community. These differences in behavior among non-whites have sociological justifications: it has been observed that when a community is or has been socially excluded from a dominant group, some will identify with the dominant culture whereas others may reject it (Akerlof, 1997, Akerlof and Kranton, 2000).

To be more precise, there are two key aspects of the preferences described in (2) and (3): being a status-seeker or a conformist and the intensity (captured by $e_{B S}$ or $\left.e_{B C}\right)$ of belonging to this group. These are basically the two "initial" conditions or the social environment of non-whites and they are defined with respect to the family, friends and neighbors. For example, consider someone who is born and raised in a very traditional Pakistani family very attached to their ethnic and cultural values (in terms language and religion that are different to the ones of the majority). According to our defintion, he/she will be considered as a conformist and his/her preferences will be given by (3). If, in addition, this individual grew up in a neighborhood (i.e. location) that is predominantly of the same ethnic group (Pakistani), then his/her $e_{B C}$ will be quite high. Observe that this does not imply that this individual will necessarily choose to distant himself/herself with whites, i.e. choose a $x$ close to 1 . This will be determined in the first stage of our model. However, it is clear that being born as a conformist (or more exactly in a conformist family) and raised in a very homogenous neighborhood (of the same ethnic group) will strongly influence this choice since they will experience strong social and peer pressures to abide by the norm of their community. On the contrary, a non-white born is a very assimilated family and raised in an almost-white neighborhood will be defined as a status-seeker with a high $e_{B S}$ and will be more likely to choose a $x$ close to zero.

\subsection{Social networks and the job acquisition rate}

Let us now describe the way the labor market operates. Here we focus on jobs that are available to both whites and non-whites, i.e. jobs for which whites and nonwhites compete for. This means that we are not interested in self-employment and in jobs that are only available to non-whites (because for example it implies knowing the language of the community).

At any moment of time, workers can either be employed or unemployed. We assume that changes in employment status (employment versus unemployment) are governed by a continuous-time Markov process. Firms are assumed to use "local" or informal methods so that jobs can mainly be obtained through word-of-mouth communications (for example firms do not advertize their vacancies but transmit the information about them only to their employed workers, who, in turn, give this information to their "friends"). In our framework, there is a two-stage procedure to obtain a job. First, workers must have a job contact with a firm (through their social network) and then a job match with this firm (as for example in Pissarides, 
2000, ch.6). The first stage requires that unemployed workers acquire information about jobs (this process will be detailed below) in order to establish a contact. In the second stage, the match is automatically realized for whites, whereas it is realized with probability $m<1$ for any non-white worker. This is because we assume that there are two types of firms in the economy: non-discriminating firms (in proportion $m$ ) and discriminating firms (in proportion $1-m$ ). So when a non-white worker has a contact with a firm, this job contact is transformed into a job match only if the firm does not discriminate against non-whites. The probability $1-m$ can represent the prejudices of employers who dislike associating with non-white workers (see Becker, 1957). Observe that $m$ does not depend on $x$. This means that labor market discrimination is not affected by the norm that a non-white adopts. In other words, if a non-white chooses to totally adopt the white's culture $(x=0)$, he/she will be seen by a discriminatory employer exactly as any other non-white that has chosen to totally reject the white's culture $(x=1)$.

We assume that job contacts randomly occur at an endogenous rate $\theta_{W}$ for whites and $\theta_{i}(x)$ for a non-white worker of type $i=B S, B C$, located at a "distance" $x$ from the white's norm while the exogenous job separation rate is $\delta$. In this context, the job acquisition rate (that is the transition rate from unemployment to employment) is the product of the job contact rate and the probability of a job match. Since whites always transform a job contact into a job match, their job acquisition rate is equal to their job contact rate $\theta_{W}$. For non-whites, the job contact rate must be multiplied by $m$ (the probability that the contacted firm is not discriminating).

Let us now determine the job contact rate for all workers. For a white worker, we have

$$
\theta_{W}=\mu+\lambda s_{W}
$$

whereas, for a worker of type $i=B S, B C$, located at a "distance" $x$ from the white's norm, it is given by:

$$
\theta_{i}(x)=\mu+\lambda s_{i}(x) \quad i=B S, B C
$$

where $\mu>0$ is the common information about jobs available to anyone (independently of race or space), $s_{W}$ and $s_{i}(x)$ denote the local social network of respectively whites and non-white workers of type $i$ located at $x$, and $\lambda$ is a positive parameter that measures the impact of social network on the job contact rate.

In the specification we have chosen, the job contact rate only depends on the amount of information workers can gather about job opportunities. Formulas (4) and (5) assume that a given level of information is available to anyone and that this level of information may be altered through social networks. In other words, besides the common knowledge factor, there is another way of learning about jobs: employed 
workers hear about the job on the workplace and transmit this information to their "friends".

Let us now define what we mean by friends and social networks. The local connections that whites and individuals from a given group $i$ can use to find a job are respectively measured by $s_{W}$ and $s_{i}(x)$, which we assume to be a positive function of that group's employment rate, i.e. respectively $1-u_{W}$ and $1-u_{i}, i=B S, B C$. In other words, when the unemployment rate is high among a particular group, individuals of that group have few connections that can refer them to jobs and their social network is poor (Calvo-Armengol, 2000, Calvo-Armengol and Zenou, 2001, Montgomery, 1991, Mortensen and Vishwanath, 1994, Topa, 2001). This is because, in our model, only the employed can transmit information about jobs. In this respect, the employment rate measures the quality of a group's social network.

As far as whites are concerned, individuals only use connections with other whites so that their social network is simply defined by:

$$
s_{W}=1-u_{W}
$$

For non-whites, the social network will partly depend on their location in the social space. Indeed, non-whites benefit from their own connections to jobs (i.e. their own employment rate) and also from part of the social network of whites. We have:

$$
s_{i}(x)=\alpha(x)\left(1-u_{W}\right)+(1-\alpha(x))\left(1-u_{i}\right) \quad i=B S, B C
$$

with $\alpha(x) \in[0,1], \forall x$, and $\alpha^{\prime}(x)<0$. For simplicity and without loss of generality, we assume that

$$
\alpha(x)=1-x
$$

which implies that $\alpha(0)=1$ and $\alpha(1)=0$. In this formulation, two different social networks affect the social network of non-white workers. The first one, the white's social network, $1-u_{W}$, strongly depends on the choice of $x$ in the social space. So, if for example the non-white individual is very much willing to adopt the white's norm, i.e. $x$ close to zero, and thus spends most of his/her time with white people, then he/she benefits very much from the social network of whites, i.e. $\alpha(x)$ is close to one. The second network is related to the individual's group and also depends on $x$. If, for example, some conformists are very reluctant to adopt the white's culture and want to essentially interact with non-whites of the same type $(\alpha(x)$ is close to zero), then they will mainly benefit from the social network of conformists.

The general idea here is that, the more time one spends with the white community, the less time he/she spends with his/her own community. In a geographical context, this will be even more true since non-whites living in predominately nonwhite (white) neighborhoods will (not) interact very much with other non-whites because of the physical separation between communities. What is crucial here is 
that there is an externality of being "close" to whites. This externality causes the employment rate of non-whites to be positively affected by the employment rate of whites. However, depending on the value of $x$ (the willingness to interact with whites or to adopt the white's culture), non-whites can benefit more or less from whites' connections to jobs.

If, as we will see below, whites have the best connections to jobs (because there are less discriminated against since most of the employers, both in the US and the UK, are whites), then equations (6) and (7) capture the fact that there is a cost (in terms of labor market outcomes) to live in a predominantly white society and not willing to adopt the white's norm.

\subsection{The two-stage equilibrium}

As stated above, there are two stages. In the first stage, depending on being statusseeker or conformist, non-white workers choose their location $x$ in the social space (we have imposed the location $x=0$ for whites). In the second stage, the labor market outcomes (i.e. the unemployment rate and the probability to find a job) of each white and each type of worker $i=B S, B C$ are determined. Because of backward induction, we solve the second stage first.

We have seen that changes in the employment status of a white and non-white worker of type $i=B S, B C$ are governed by a time continuous Markov process in which $\theta_{W}$ and $m \theta_{i}(x)$ are respectively the group-specific transition rate (defined by (4) and (5)) and $\delta$ is the job destruction rate. As a result, plugging (6) in (4), the probability to find a job for whites is equal to

$$
\theta_{W}=\mu+\lambda\left(1-u_{W}\right)
$$

whereas, for non-whites, by plugging (7) in (5) and using (8), they are respectively given by

$$
m \theta_{i}(x)=\mu m+\lambda m\left[1-u_{W}-x\left(u_{i}-u_{W}\right)\right] \quad i=B S, B C
$$

In steady state, flows into and out of unemployment are equal. We thus have

$$
u_{W}=\frac{\delta}{\theta_{W}+\delta}
$$

for whites whereas non-whites of type $i=B S, B C$ and location $x$, we obtain:

$$
u_{i}(x)=\frac{\delta}{m \theta_{i}(x)+\delta}
$$

where $u_{i}(x)$ denotes the unemployment rate of workers of type $i=B S, B C$ as a function of $x$ the location in the social space. Lemma 1 in the Appendix shows that we have $u_{W}<u_{B S}$ and $u_{W}<u_{B C}$ whatever the location chosen in the first stage 
by non-whites. Lemma 2 in the Appendix shows that when $\mu>\lambda$, the solutions of (11) and (12) are unique, strictly positive, strictly between 0 and 1 , and respectively given by (13), (14) and (15).

Let us now solve the first stage of the model. We are now able to calculate the expected utilities of each group. To do that, we assume perfect capital markets with a zero interest rate, ${ }^{4}$ which enable workers to smooth their income over time as they enter and leave unemployment: workers save while employed and draw down on their savings when out of work. At any moment, the disposable income of a worker is thus equal to that worker's average income over the job cycle. Therefore, using (1), the expected utility of a white worker is equal to

$$
\begin{aligned}
E V_{i}(x) & =\left(1-u_{W}\right) V_{W E}+u_{W} V_{W U} \\
& =y_{E}-u_{W}\left(y_{E}-y_{U}\right)
\end{aligned}
$$

For a status-seeker located in $x$, using (2), it is given by:

$$
\begin{aligned}
E V_{B S}(x) & =\left(1-u_{B S}(x)\right) V_{B S E}(x)+u_{B S}(x) V_{B S U}(x) \\
& =y_{E}-e_{B S} x-u_{B S}(x)\left(y_{E}-y_{U}\right)
\end{aligned}
$$

whereas for a conformist, using (3), we have

$$
\begin{aligned}
E V_{B C}(x) & =\left(1-u_{B C}(x)\right) V_{B C E}(x)+u_{B C}(x) V_{B C U}(x) \\
& =y_{E}+e_{B C} x-u_{B C}(x)\left(y_{E}-y_{U}\right)
\end{aligned}
$$

where $u_{i}(x), i=B S, B C$ is determined by (12).

We are now able to state our main theoretical result.

Proposition 1 Assume $\mu>\lambda$.

(i) Non-white status-seekers always choose to totally adopt the white's norm, i.e. $x_{B S}^{*}=0$.

(ii) Depending of how strong their preferences against whites are relatively to the wage premium of being employed, non-white conformists can choose to adopt or to reject the white's norm. More precisely, by using the value of $u^{\prime}(0)$ and $u^{\prime}(1)$ in (21) and (22), we have:

\footnotetext{
${ }^{4}$ When there is a zero interest rate, workers have no intrinsic preference for the present so that they only care about the fraction of time they spend employed and unemployed. Therefore, the expected utilities are not state dependent. For example, since a white worker spends a fraction $\theta_{W} /\left(\theta_{W}+\delta\right)$ of his lifetime employed and a fraction $\delta /\left(\theta_{W}+\delta\right)$ unemployed, his average income is equal to $\frac{\theta_{W}}{\theta_{W}+\delta} y_{E}+\frac{\delta}{\theta_{W}+\delta} y_{U}$. The same analysis applies for status-seeker and conformist blacks.
} 
(iia) If $e_{B C} /\left(y_{E}-y_{U}\right) \leq u^{\prime}(0)$, non-white conformists always choose to totally adopt the white's norm, i.e. $x_{B C}^{*}=0$ and, as a result, have the same probability of being employed as non-white status-seekers.

(iib) If $u^{\prime}(0)<e_{B C} /\left(y_{E}-y_{U}\right)<u^{\prime}(1)$, non-white conformists choose to partially adopt the white's norm, i.e. $0<x_{B C}^{*}<1$ but have a lower probability of being employed than non-white status-seekers.

(iic) If $e_{B C} /\left(y_{E}-y_{U}\right) \geq u^{\prime}(1)$, non-white conformists will choose to totally reject the white's norm, i.e. $x_{B C}^{*}=1$ and will have a much lower probability of being employed than non-white status-seekers.

Proof. See the Appendix.

Non-white status seekers always choose to totally adopt the white's norm, i.e. $x_{B S}^{*}=0$, and thus to very much interact with whites. Indeed, their environment is already very assimilated and very open to whites and they anticipate that interacting with whites is beneficial because it increases their chance to find a job. As a result, whatever the value of $e_{B S}$, there is no reason for them not to choose $x_{B S}^{*}=0$. For non-white conformists, the story is different since there are two opposite forces that counteract. On the one hand, they would like to reject the white's norm because of the social and peer pressure, but, on the other, they are attracted to whites because of the positive consequences in the labor market. The first-order condition of the maximization problem of conformists clearly shows these two opposite forces. It is given by:

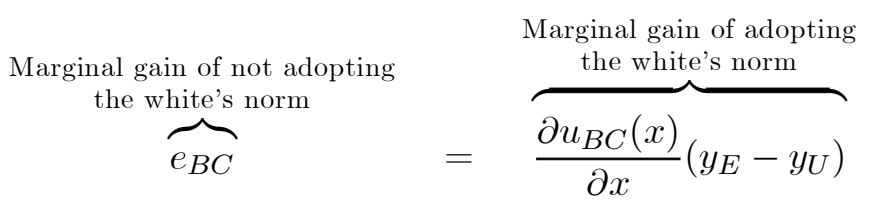

As it can be seen, choosing $x$ imposes a trade off. Indeed, increasing $x$ (being further away from the white's norm) increases $e_{B C} x$ and their expected utility since conformists are happier to be closer to their own community, but decreases their chance to obtain a job since $u_{B C}(x)$ increases $\left(u_{B C}^{\prime}(x)>0\right.$ because the further away a nonwhite is from the white community, the poorer is his/her social network). Proposition 1, case (iic), shows that if the social environment (family, friends, neighbors) is very strong, i.e. $e_{B C}$ high, compared to the wage premium of being employed, then non-white conformists will choose to distance themselves from the white's community, even though they anticipate that it implies a lower chance of being employed. If this is not the case (cases (iia) and (iib)), then conformists may partially or totally integrate the white's culture. This shows the crucial role of family and peer pressures as well as welfare policies in the choice of assimilating to the white's culture. If there is a little premium to be employed (because for example the unemployment benefits are too high), then there is less incentive to interact with whites for people who would not naturally interact with them. 
As stated above, language and religion are ones of the main attributes that define and differentiate status-seekers to conformists. As a result, Proposition 1 indicates that non-whites who have different language and religion than that of the majority group (whites) and are strongly attached to them (these are conformists with high $\left.e_{B C}\right)$ will be less likely to assimilate to the white's norm and more likely to experience adverse labor outcomes. There is an important literature that shows that the lack of fluency in the English language has indeed adverse effects on both assimilation and labor market outcomes of non-white workers (especially immigrants). This literature begins with Chiswick (1978) and has been studied further by, among others, McManus, Gould and Welch (1983) and Borjas (1994) for the US, and Dustmann and Fabbri (2000) for the UK. Concerning religion, there is a small literature on the economic consequences of religion (see in particular Iannaccone, 1998) but, to our knowledge, not on the impact of religion on the degree of assimilation and labor market outcomes of immigrants. A notable exception is Lazear (1999) who focuses on cultural differences (religion is obviously part of the culture of people) between the minority and the majority group. He shows that individuals from minority groups are more likely to adopt the culture of the majority when the minority group accounts for a small proportion of the total population.

More generally, this model shows that, in equilibrium, whites and conformists are in general respectively the most and the less favored group in terms of labor market outcomes. Indeed, whites are not discriminated against and thus benefit from a good social network. To the contrary, as soon as $e_{B C} /\left(y_{E}-y_{U}\right)>u^{\prime}(0)$, conformists have a poor social network (in particular because they do not like to interact with whites) and are discriminated against. Therefore, non-white conformists have the worse labor market outcomes because unemployment is rampant and peer pressure (to conform to the community's norms and accept adverse racial preferences) has negative effects on those who are sensitive to it. These results are partly based on the fact that information about jobs can only be acquired through social networks (employed friends). In this respect, conformists are totally isolated from jobs and thus have little information on job opportunities. The situation is different for status-seekers since they are less isolated from jobs because they have contacts with whites.

Of course, we cannot rank (expected) utilities since, for example, conformists that generally experience high unemployment rates can be quite "happy" since they do not interact very much with whites (we cannot however compare the utilities of the different communities since individuals have different preferences). So the basic result here is that conformists that do not want to interact with whites "pay" in some sense the price of this behavior by experiencing high unemployment rates and a low probability to find a job compared to the other non-whites that are more willing to adopt the white's norm. Once again, this does not imply that there are 
worse off.

We would now like to test the result of Proposition 1 using British data. Our empirical strategy is in two stages. First, by focusing on six non-white ethnic groups (Caribbean, Indian, Pakistani, African-Asian, Bangladeshi, and Chinese), we will try to decipher the factors that drive the "location" $x$ in the social space of nonwhites. Second, we will test econometrically the impact of this "location" $x$ or the fact to belong to the conformist or the status-seeker group on the probability to be employed.

\section{Data and Descriptive Statistics}

The data we employ is derived from the Fourth National Survey of Ethnic Minorities (FNSEM) collected in 1993/94 by the Policy Studies Institute (PSI). This includes a standard set of variables capturing individual, demographic and job characteristics (see Modood et al. 1997 for details). It has the advantage that it over-samples ethnic minority groups and explicitly acknowledges the heterogeneity within the nonwhite population where the ethnic population is composed of six groups (Caribbean, Indian, Pakistani, African-Asian, Bangladeshi, and Chinese). ${ }^{5}$

At the heart of the data set is the 1991 Census. This was used to select the sample of ethnic minorities included in the survey. In particular, all electoral wards in England and Wales were divided into three bands (high, medium and low) according to the proportion of the population who were members of ethnic minorities. ${ }^{6}$ Within each band a sample of wards was chosen and within each of these selected wards a sample of addresses was picked. Interviewers then visited 130,000 addresses to identify any members of the target minority groups living there who could then be interviewed.

At each household containing adults from ethnic groups, one or two were selected for interview. Where a household had more than two eligible adults, two were chosen at random. Two questionnaires were randomly assigned to the two adults selected. Though both questionnaires had the same core set of questions they did contain a different set of secondary questions. Importantly, a majority of selected individuals were interviewed by a member of their own ethnic group either in English or in their own language, thereby maximizing the response rate and reducing any potential source of bias. Interviews were successfully obtained in 3291 ethnic households with 5196 ethnic individuals. A comparison sample containing white households was also obtained generating 2867 white interviews. ${ }^{7}$ Means and standard deviations for a

\footnotetext{
${ }^{5}$ For historical reasons Black Africans were not included. Furthermore, the survey only covers England and Wales.

${ }^{6}$ Electoral wards have been described as the geographic building blocks of the UK. There are 9,527 wards in England and Wales.

${ }^{7}$ The response rates were $61 \%$ for Caribbeans, $74 \%$ for Indians and African Asians, $73 \%$ for
} 
range of variables are given in Table 1.

As far as we are aware there is little or no empirical work examining the effects of ethnic preferences and in particular oppositional identities on labor market outcomes. This may stem in part from a lack of data but it could also stem from a fear of treading on issues that are usually the preserve of sociologists. Nevertheless, the data set we utilize contains extensive information on various aspects of an individual's ethnic preferences. ${ }^{8}$ A number of questions surrounding ethnic identity and preferences were asked of respondents including questions on identification with Britishness, identification with their own ethnic group, attitudes towards inter-marriage and preferences in terms of living in highly concentrated ethnic areas. These variables are used to gauge the extent to which there exist oppositional identities amongst ethnic minorities in the UK or to put it another way an individuals location in social space $(x)$ relative to the white majority. Other questions surrounding the importance of ethnicity include schooling decisions for children, the wearing of ethnic clothing and importance of religion were also asked but present practical (only half the ethnic sample were asked the question) and theoretical objections (the wearing of a turban by a Sikh does not necessarily represent opposition to mainstream values).

In addition gauging ethnic preferences and an individuals location in social space through subjective questions can be problematic. There is the usual issue of how reliable are individual responses and also how responses to different questions may place the same individual on quite a different position in social space relative to whites. It is also the case that individuals possess plural identities and do not just belong to just one group or community. Ethnic background then may just be one of many identities that individuals have where different identities may be invoked in particular contexts. Furthermore, identities can be chosen even when the choices are constrained and the constraints vary in strength depending on the circumstances (Sen, 2000).

In the FNSEM the importance of ethnic identification was captured by reading out two statements to interviewees:

1. In many ways, I think of myself as being British.

2. In many ways, I think of myself as [respondent's ethnic group].

Respondents were asked if they agreed or disagreed and if so, whether strongly or just a little. Table 2 and 3 summarize the responses across different ethnic groups. Both questions are essentially asking about identification with a country, with a place and its way of living and the responses do reveal the difficulty in clearly assigning our ethnic groups to different locations of the social space. Leaving aside the Chinese for a moment, it is clear that just over $55 \%$ of the remaining ethnic groups agreed

Pakistanis, $83 \%$ for Bangladeshis, $66 \%$ for Chinese and $71 \%$ for Whites.

${ }^{8}$ Other datasets such as the Labour Force Survey are seriously lacking in this respect. 
that they thought of themselves as British. The group that agreed the most are the African-Asians (71\%) and the group that agreed the least are the Bangladeshis (56\%). The Caribbeans are the most likely to disagree (34\%). Other evidence from this data set and not presented here reveals that around a quarter of British born Caribbeans did not think of themselves as being British. This contrasts with the West Indian migrants of the 1940s and 1950s who by most accounts thought of themselves as British and often talked of coming to "the mother country" (Modood et al. 1997). The Chinese in Table 1 stand out since roughly equal percentages agreed and disagreed with the notion of being British ( 44 and $41 \%$ respectively). At least in terms of this question the Chinese seem to sit at both extremes in terms of their location in social space.

Table 3 confirms that there is a strong sense of ethnic identity amongst minority groups. Over $80 \%$ of each group either agreed strongly or agreed that they thought of themselves in terms of their own ethnic group. The figures for those who disagreed are quite small - the highest is for Caribbeans with around $10 \%$ of them not thinking of themselves as Caribbean. Therefore, whilst a significant minority disagree with the notion of being British, this is not the case when it comes to their own ethnic identity. Furthermore, the answers to the two questions reveal that there may not be a conflict in identities. For example, being British and being Bangladeshi does not compete in the minds of most respondents. This suggests that identities can indeed be multiple (Sen, 2000).

Table 4 provides some data on another dimension of identity, namely marriage and in particular attitudes to inter-marriage. Intermarriage is considered to be a measure of social assimilation and also a factor producing it (Pagnini and Morgan, 1990). On the other hand some ethnic and religious groups regard interethnic marriage as a potential threat endangering and undermining ethnic identities. In the FNSEM individuals were asked "If a close relative were to marry a white person would you not mind, would you mind a little, would you mind very much?" Here significant percentages of the three South-Asian groups said they would mind very much with the greatest hostility being among the Pakistani population (37\% of them say they would mind very much a mixed marriage). On this dimension significant numbers of South-Asians are conformists. A majority of the other groups said that they would not mind and amongst Caribbeans (8\%), African Asians (13\%) and the Chinese $(7 \%)$ the percentages that would mind very much are quite small.

An area of controversy in the UK and the US has been the role of schools in keeping different ethnic communities separate from each other. In one recently published UK report it was argued that schools dominated by one race or faith should offer at least a quarter of their places to pupils from other backgrounds (Building Cohesive Communities, 2001). At the same time the UK government is committed to the expansion of church and faith-sponsored schools. A number of questions were 
asked in the FNSEM to assess the relevance of ethnicity in influencing the kind of school that people wanted for their children. First, how important is ethnicity in choosing a school? Second, what proportion of one's ethnic group would you like in your children's school? The descriptive statistics are given in Table 5 and 6 . In Table 5 the most common answer is that it would have no influence. In fact, it was deemed an important consideration for only a quarter of African-Asians and Indians and for around one third of Caribbean's and Bangladeshis. Only one in ten Chinese thought it important. Table 6 gives some data on the preferred proportion of one's ethnic group in a school. Of those who did have a preference $40 \%$ of Caribbeans and $38 \%$ of Pakistanis wanted a school with $50 \%$ or more from their own ethnic group. For the African Asians, Indian, Bangladeshi and Chinese groups the figures are much smaller $(24 \%, 22 \%, 29 \%$ and $11 \%$ respectively).

\section{Measurement and Estimation}

We would like now to test our theoretical model (section 2). For that, our empirical analysis focuses on whether ethnic preferences in terms of individual location in social space matters in terms of the probability of being in employment. We do not examine the effects on earnings since the response rate for earnings in the FNSEM was poor especially for the South Asian groups. In any case, it could be argued that the most important dimension of economic disadvantage is employment and not earnings. According to Blackaby et al. (1997) "the lack of jobs is a major factor of the discriminatory process and may ultimately be more socially damaging".

To gauge the effects upon employment, we estimate a set of employment equations using probit estimation. Employment is coded unity and zero otherwise using the ILO definition. Location in social space enters our equation in two forms. First, a binary dependent variable for each of our identity related questions discussed in the previous section. In particular, the extreme values of each of the variables are coded one and are taken to encapsulate an oppositional identity ( $x$ is closer to 1 ) and all other responses are coded zero. For example, if an individual strongly disagrees with inter-marriage that is coded one and zero if not (smind). Full details of the oppositional identity variables are given in Table 7 . Second, we take the responses from the four variables in Table 7 (nbrit, oethnic, smind and schch) and aggregate them. If an individual gives an extreme response for at least two of the

four questions, then he/she is considered as extremely oppositional (i.e. he/she is very conformist) and the aggregate variable is coded one and zero otherwise (opid).

A standard set of covariates are included in the estimating equation. We have age and its square, gender, married and presence of children. The marriage term enters in the form of two dummy variables intended to capture potential assimilation effects: married to someone from own ethnic group (marown) and married to someone from 
another ethnic group (intmar). Further assimilation effects are captured via a set of UK and foreign qualification dummies, a dummy capturing language fluency, a born in the UK dummy, years since arrival in the UK, regional dummies, and dummy variables for local ward unemployment. Also included is an ethnic concentration dummy that is intended to capture any ethnic enclave effect (oethcon). In particular, some minorities may choose to live within their communities in order to gain access to ethnic shops, places of worship, display greater racial or religious solidarity or in order to socially interact in ones own language. ${ }^{9}$ On the other hand individual choices may not be freely made and may reflect discrimination in housing or in employment. Regardless of the mechanism at work ethnic enclaves may reduce the probability of being in work. As argued earlier interactions between ethnic minorities and the white majority may improve ethnic minorities' social capital and job finding networks (Weinberg, 2000).

To capture the influence of spatial constraints we also included a dummy for whether the respondent has access to a private vehicle (owncar) and whether they are owner-occupiers (ownoccupier). Having access to a private vehicle opens up the potential area of job search and improves the possibility of getting employment (Raphael and Stoll, 2000). Other evidence reveals that ethnic groups in the UK are more likely to use public transport relative to whites with non-whites and the Bangladeshis having the lowest car ownership (Owen and Greene, 2000). The importance of household tenure in predicting unemployment is well established (Hughes and McCormick, 1987) and owner-occupier rates have been found to be higher for Indians relative to whites with non-white Caribbeans and Bangladeshis more likely to be renting from the social landlord sector than the private sector (DETR, 2000). ${ }^{10}$

The main problem here is that an individual's location in social space may in fact be endogenous. This we tested and found using the Smith-Blundell test of exogeneity that three of our identity terms were endogenous (smind, oethnic and nbrit). Thus, we undertake a two-stage instrumental variable estimation, where in the first stage we estimate a set of oppositional identity probit equations with appropriate instruments. In the second stage, we insert the predicted values into the employment probit.

The preference's equation is identified with a set of appropriate instruments. These capture the influence of prior experiences or preferences and include whether individuals have experienced racial harassment (rharra), if they prefer a school of their own religion for their children (schrelig), and if their parents made the decision in choosing their wife or husband (arrmar). These do not have a direct bearing on

\footnotetext{
${ }^{9}$ On the other hand there may be "mainstreaming" of specialist goods as major supermarkets supply a wide range of ethnic goods.

${ }^{10}$ Car ownership and housing tenure may of course be endogenous in the employment equation (Blackaby et al. 1997).
} 
whether someone is employed or not other than through the effects of these variables on the probability of being oppositional.

Throughout our estimations the sample utilized is the working age population of males (aged 16 to 64) and females (aged 16-59). Given their very small numbers in the data set the Chinese are excluded from the analysis and the Bangladeshi and Pakistani group are combined on the basis that they are both overwhelmingly Muslim, they face similar levels of relative disadvantage in the labor market (Blackaby et al. 1999) and emanate from rural areas in their origin country. All results reported are marginal effects.

\section{Empirical Results}

\subsection{What determines an oppositional identity?}

Table 8 presents the results from our preferences' equations (first stage). All three instruments behave as expected and are jointly statistically significant at all conventional levels of significance. Having experienced racial harassment matters for four out of five identity regressions. Those who prefer a school of their own religion (schrelig) are consistently more likely to be oppositional across all five regressions. Having experienced an arranged marriage (arrmar) is positively related to an oppositional stance in three cases (smind, nbrit and opid). The strongest effect is evident for smind where those who have had an arranged marriage are more likely to strongly mind inter-marriages.

Separate estimations are undertaken for each of the identity terms and the aggregate identity variable (opid). Ethnic preferences may be a function of the extent to which individuals have been economically or socially excluded from a dominant group. Those who cannot gain employment may choose to adopt an oppositional identity and therefore a place close to one in social space $(x)$. This is captured to some extent by the series of ward level unemployment variables. Though the dummies are correctly signed statistical significance is rarely evident. Thus there is little evidence in this analysis that lack of employment at a local level reinforces any oppositional tendencies.

In accordance with our theoretical model residing in a very homogenous neighborhood does seem to matter. In particular, living in a high ethnic concentration area (over a third of the population in your area is from your own ethnic group) seems to reinforce any oppositional stance since this makes it more likely that individuals will strongly disagree with being British (nbrit) and raises the probability that individuals strongly align themselves with their own ethnic group (oethnic).

The dummies for ethnic groups reveal that the African-Asians are the least oppositional ( $x$ is closer to zero) relative to the omitted category of Indians. They are less likely to strongly disagree with being British, are less likely to align themselves 
strongly with their own ethnic group and are less likely to strongly disagree with inter-marriages. They are closest to our conception of status seekers. The other groups are more difficult to characterize in this manner. The Pakistani/Bangladeshi display oppositional identities on only one dimension (schcon) and the Caribbean group displays oppositional identities on two dimensions (schcon and nbrit). However, there is evidence from the estimates that Caribbeans are less likely to see themselves as British. This is rather surprising since many Caribbeans who migrated to the UK in the 1940s and 1950s did think of themselves as British. In terms of minding inter-marriages Caribbeans are less likely to be hostile. This is expected since half of the live in partners of British born Caribbean men were white females (Modood et al. 1997). Indeed, being married to a white female may be an indicator of assimilation and could be seen as a step up the white social ladder and so be related to career aspirations (Berthoud, 2000 and Meng and Gregory, 2001). This is supported by our dummy for inter-marriage (intmar) which is associated with less hostility to inter-marriages and the notion of being British.

With respect to qualifications you would expect that those with higher qualifications might benefit more from integration and so be less extreme in their preferences. There is no evidence for this in our results. However, having foreign qualifications reduces the individuals emphasis on his or her own ethnicity and also reduces the probability that individuals will strongly mind inter-marriages. Language fluency also matters in our results. The basic argument here is that those with low levels of English language proficiency may identify more with their ethnic grouping and various attributes of their identity. Our results support this and find that being fluent in English and thus being able to interact more with the white majority seems to imply less of an oppositional identity (in four out of five identity regressions).

Being UK born is unsurprisingly associated with a less oppositional stance for three of the identity variables (nbrit, oethnic and opid). As one would expect the longer an individual has been in the UK (yrsmg) the less hostile they are to being British (nbrit) and the less they emphasize their own ethnic group (oethnic).

\subsection{What are the effects on employment?}

The results from our instrumental variable employment probits are given in Table 9 (second stage). For comparison we also provide in Table 10 the non-instrumental variables estimates. As stated earlier the identity terms capture to some extent the willingness of non-whites to interact with whites. The question then is whether there is a negative externality from not associating with the majority group in term of a loss in employment. This is indeed what is found but for only two out of four of the oppositional identity terms. Non-whites who strongly disagree with the notion of being British are less likely to be employed (by around 7\%). This compares with a penalty of around $10 \%$ where we do not correct for the endogeneity of identity (Table 
10). There is also a cost associated with being very hostile to inter-marriages; those who strongly disagree with inter-marriages incur an employment probability penalty of around $6.5 \%$. Having an identity that is closely tied to ones ethnic group does not generate an employment penalty (oethnic). Where we combine the four oppositional dummies, as in opid, we find that having an oppositional identity does reduce the probability of being in employment by around $6 \%$. This compares $9 \%$ where we do not correct for the endogeneity of ethnic preferences.

The coefficients on age, age-squared and children behave as expected. There is no discernible effect arising through gender thus separate estimates for males and females are not attempted. A clear benefit arising from interethnic marriage is evident. In three of the regressions being married either within ones own group or outside is associated with a higher probability of being in employment relative to being single (the omitted category) and the effect is larger for those who marry outwith their own community (20\% as opposed to 13-15\%). The presence of children reduces the probability of employment where this may stem from the disincentive effects arising through the benefit system that links benefits to family size. For the ethnic dummies we find that Pakistanis and Bangladeshis, who are both overwhelmingly Muslim, are less likely to be employed relative to Indians (the omitted category) across all regressions and this effect is strong at approximately $24 \%$.

It has been suggested that one mechanism for overcoming disadvantage is to improve educational qualifications (Leslie and Drinkwater, 1999). Though little is happening with respect to foreign qualifications, possessing a UK degree does seem to matter. Having a UK degree raises the probability of being employed of ethnic groups in the UK by up to $25 \%$. The lack of any effect for foreign qualifications may reflect some doubt amongst native employers about the quality and portability of foreign qualifications (Friedberg, 2000).

There is clearly a linguistic advantage for those who are fluent in English. This fits with other research that finds that ethnic group differences in communication styles have an important influence on the labor market success of low-income nonwhites in the US (McManus, Gould and Welch, 1983; Lang, 1986; Cornell and Welch, 1996; Lazear, 1999). The positive relationship between language fluency and employment perhaps reflects improved job search strategies, an ability to convince potential employers of the value of their qualifications or the possibility that for certain jobs (e.g. in the service sector) fluency is an entry requirement (Dustmann and Fabbri, 2000).

It is also found that the longer have non-whites been in the UK the more likely they are to work. Being resident in an ethnic enclave only matters in regression (3) where the identity term is nbrit: living in an ethnically concentrated neighborhood is detrimental to the probability of being in employment. Stronger spatial effects are apparent when examining home and vehicle ownership. Those individuals who 
are owner-occupiers and those who own their own car are more likely to be in employment. Car ownership for ethnic groups may be seen as ameliorating any spatial constraint thereby improving the chances of employment (Thomas, 1998). In both cases job search is less restricted raising the probability of being in work. Their local economic environment may also determine the employment position of minorities. This is captured via a set of ward level unemployment dummies. However, there is no evidence that higher local unemployment results in a lower probability of obtaining employment.

\section{Conclusion}

This papers tries at a theoretical and empirical level to ascertain the effects of an oppositional identity amongst ethnic groups upon the probability of being employed in the labor market. In our theoretical model ethnic preferences are predicted to reduce labor market success where preferences are gauged in terms of remoteness or otherwise to white norms. Our empirical findings do indicate considerable heterogeneity in the non-white population in terms of preferences. Though the African-Asian ethnic group most clearly conforms to our theoretical notion of status seekers in the sense that they adopt less extreme oppositional preferences the other groups are much more difficult to characterize in this manner since there are differences depending on how one measures ethnic preferences. Nevertheless, our empirical findings do suggest that extreme ethnic preferences for non-whites are related to whether they are married to someone outwith their own community, their fluency in the English language and whether they born in and how long they have been resident in the UK. In addition, we find clear evidence that a belief in single faith schools, an experience of racial harassment and having had an arranged marriage are associated with extreme preferences.

Our results also reveal that there is an employment penalty associated with such extreme identities. Those with extreme preferences (the conformists) do experience a 6 to $7 \%$ lower probability of being in employment relative to those with less extreme views (the status seekers) depending on the measure we utilise. These effects are evident when we control for the endogeneity of ethnic preferences and a range of variables capturing assimilation effects. Sample size restrictions do not allow us to

disentangle these effects at an individual ethnic group level but future research needs to disaggregate in this manner. 


\section{References}

[1] Akerlof, G. and R. Kranton (2000)., "Economics and identity", Quarterly Journal of Economics, 115, 715-753.

[2] Akerlof, G. (1997), "Social distance and social decisions", Econometrica, 65, 10005-1027.

[3] Alesina, A. and E. La Ferrara (2001), "Who trusts others?", Journal of Public Economics, 85, 207-234.

[4] Becker, G.S. (1957), The Economics of Discrimination, Chicago: Chicago University Press.

[5] Berthoud (2000), "Ethnic employment penalties in Britain", Journal of Ethnic and Migration Studies, 26, 389-416.

[6] Blackaby, D. Drinkwater, S. Leslie, D. and P. Murphy (1997), "A picture of male ad female unemployment among Britain's ethic minorities", Scottish Journal of Political Economy, 44, 182-197.

[7] Blackaby, D. Leslie, D. Murphy, P., N. O’Leary (1999), "Unemployment among Britain's ethnic minorities", The Manchester School, 67, 1-20.

[8] Bledsoe, T., Welch, S., Sigelman, L. and M. Combs (1995), "Residential context and racial solidarity among African Americans", American Journal of Political Science, 39, 434-458.

[9] Borjas, G.J. (1994), "The economics of immigration", Journal of Economic Literature, 32, 1667-1717.

[10] Brown, M.S. (2000), "Religion and economic activity in the South Asian population", Journal of Ethnic and Migration Studies, 23, 1035-1061.

[11] Building Cohesive Communities (2001), A Report of the Ministerial Group on Public Order and Community Cohesion.

[12] Calvo-Armengol, A. (2000), "Job contact networks", Unpublished manuscript, Universitat Pompeu Fabra.

[13] Calvo-Armengol, A. and Y. Zenou (2001), "Job matching, social network and word-of-mouth communication", CEPR Discussion Paper Series 2797.

[14] Cantle Report (2001), Community Cohesion, Home Office.

[15] Chiswick, B. R. (1978), "The effect of Americanization on Earnings of foreign born men", Journal of Political Economy, 86, 897-921. 
[16] Cornell, B. and I. Welch (1996), "Culture, information, and screening discrimination", Journal of Political Economy, 104, 542-71.

[17] CRE (2002), Report on Racial Segregation in the North of England.

[18] Cutler, D. M. and E. L. Glaeser (1997), “Are ghettos good or bad?", Quarterly Journal of Economics, 112, 827-872.

[19] Delpit, L. (1995), Other People's Children: Cultural Conflict in the Classroom, New York, The Free Press.

[20] DETR (2000), Survey of English Housing, London: HMSO.

[21] Dustmann, C. and F. Fabbri (2000), "Language proficiency and labour market performance of immigrants in the UK", IZA Discussion Paper No. 156.

[22] Friedberg, R.M. (2000), "You can't take it with you? Immigrant assimilation and the portability of human capital", Journal of Labor Economics, 18, 221-251.

[23] Hughes, G.A. and B. McCormick (1987), "Housing markets, unemployment and labour market flexibility in the UK", European Economic Review, 31, 615-645.

[24] Iannaccone, L.R. (1998), "Introduction to the economics of religion", Journal of Economic Literature, 36, 1465-1496.

[25] Ihlanfeldt, K. and B. Scafidi (2002), "Black self-segregation as a cause of housing segregation. Evidence from the multi-city study of urban inequality", Journal of Urban Economics, 51, 366-390.

[26] Lang, K (1986), "A language theory of discrimination", Quarterly Journal of Economics, 101, 363-82.

[27] Lazear, E.P. (1999), "Culture and language", Journal of Political Economy, 107, S95-S126.

[28] Leslie, D. and Drinkwater, S. (1999), "Staying on in full-time education: Reasons for higher participation among ethnic minority males and females", Economica, 66, 63-77.

[29] Loury, G.C. (1999), "Social exclusion and ethnic groups: The challenge to economics", Annual World Bank Conference on Development Economics, Washington, D.C.

[30] McManus, W.S., Gould, W. and F. Welch (1983), "Earnings of hispanic men: The role of English language proficiency", Journal of Labor Economics, 1, 101130 . 
[31] Meng, Xin and R.G. Gregory (2001), "Intermarriage and the economic assimilation of immigrants", mimeo.

[32] Modood, T. et al. (1997), Ethnic Minorities in Britain: Diversity and Disadvantage, London: Policy Studies Institute.

[33] Montgomery, J. (1991), "Social networks and labor-market outcomes: Toward an economic analysis", American Economic Review, 81, 1408-1418.

[34] Mortensen, D.T. and T. Vishwanath (1994), "Personal contacts and earnings. It is who you know!", Labour Economics, 1, 187-201.

[35] Ogbu, J.U. (1997), "Beyond language: ebonics, proper English and identity in a Black American speech community", Unpublished manuscript, University of California at Berkeley, Department of Anthropology.

[36] Owen, D and A. Green (2000), "Estimating commuting flows for minority groups in England and Wales", Journal of Ethnic and Migration Studies, 26, 581-608.

[37] Pagnini, D.L. and S.P. Morgan (1990), "Intermarriage and social distance among U.S. immigrants at the turn of the century", American Journal of Sociology, 96, 405-432.

[38] Pissarides, C.A. (2000), Equilibrium Unemployment Theory, 2nd edition, Cambridge: MIT Press.

[39] Raphael, S. and M. Stoll (2000), "Can boosting minority car ownership rates narrow inter-racial employment gaps", Unpublished manuscript, University of California at Berkeley.

[40] Selod, H. and Y. Zenou (2002), "Does city structure affect the labor market outcomes of black workers?", Unpublished manuscript, University of Southampton.

[41] Sen, A.(2000), Other People, British Academy Lecture.

[42] Thomas, J. (1998), "Ethnic variation in commuting propensity and unemployment spells: Some UK evidence", Journal of Urban Economics, 43, 385-400.

[43] Topa, G. (2001), "Social interactions, local spillovers and unemployment", Review of Economic Studies, 68, 261-295.

[44] Weinberg, B. (2000), "Black residential centralisation and the spatial mismatch hypothesis", Journal of Urban Economics, 48, 110-134.

[45] Wilson, W.J. (1987), The Truly Disadvantaged, Chicago: Chicago University Press. 


\section{APPENDIX}

Lemma 1 Whatever the location $0 \leq x \leq 1$ chosen by non-whites, the unemployment rate of whites is always lower than that of non-whites, i.e.

$$
u_{W}<u_{B S} \text { and } u_{W}<u_{B C}
$$

Proof. This is obvious since all whites are located in $x=0$ and they are not discriminated against. So even if non-whites choose the "best" location in terms of labor market outcomes, i.e. $x=0$, they will still experience a higher unemployment rate because of labor discrimination.

Lemma 2 Assume $\mu>\lambda$. Then

(i) The unemployment rate of whites is uniquely determined, strictly positive, strictly between 0 and 1 and is given by:

$$
u_{W}=\frac{\delta+\mu+\lambda-\sqrt{(\delta+\mu+\lambda)^{2}-4 \lambda \delta}}{2 \lambda}
$$

(ii) For non-whites, we have:

(iia) When $x=0$, the unemployment rate of both status-seekers and conformists is uniquely determined, strictly positive, strictly between 0 and 1 and is given by:

$$
u(0) \equiv u_{B S}(0)=u_{B C}(0)=\frac{\delta}{\delta+\mu m+\lambda m\left(1-u_{W}\right)}
$$

(iib) When $x=1$, the unemployment rate of both status-seekers and conformists is uniquely determined, strictly positive, strictly between 0 and 1 and is equal to:

$$
u(1) \equiv u_{B S}(1)=u_{B C}(1)=\frac{\delta+(\mu+\lambda) m-\sqrt{[\delta+(\mu+\lambda) m]^{2}-4 \delta \lambda m}}{2 \lambda m}
$$

(iic) When $0<x<1$, the unemployment rate of both status-seekers and conformists is uniquely determined, strictly positive, strictly between 0 and 1 and is given by:

$$
u_{B S}(x)=u_{B C}(x)=\frac{\delta+\mu m+\lambda m\left[1-(1-x) u_{W}\right]-\sqrt{\Delta}}{2 \lambda m x}
$$

where

$$
\Delta=\left[\delta+\mu m+\lambda m\left[1-(1-x) u_{W}\right]\right]^{2}-4 \delta \lambda m x
$$


Proof. ( $i$ ) The unemployment rate of whites is defined by (11), which is equivalent to:

$$
\lambda u_{W}^{2}-(\delta+\mu+\lambda) u_{W}+\delta=0
$$

The discriminant is $\Delta_{W}=(\delta+\mu+\lambda)^{2}-4 \lambda \delta$. If $\mu>\lambda$, then $\Delta_{W}>0$. We thus have two distinct roots that are given by

$$
u_{W}=\frac{\delta+\mu+\lambda \pm \sqrt{(\delta+\mu+\lambda)^{2}-4 \lambda \delta}}{2 \lambda}
$$

and both of them are strictly positive. Let us show that the root with the highest value is strictly greater than 1 . This is equivalent to

$$
\delta+\mu+\sqrt{(\delta+\mu+\lambda)^{2}-4 \lambda \delta}>\lambda
$$

which is always true as soon as $\mu>\lambda$. Let us show that the root with the lowest value is strictly less than 1 . This is equivalent to

$$
\delta+\mu-\lambda<\sqrt{(\delta+\mu+\lambda)^{2}-4 \lambda \delta}
$$

or

$$
\begin{gathered}
4 \lambda \delta<(\delta+\mu+\lambda)^{2}-(\delta+\mu-\lambda)^{2} \\
\Leftrightarrow \mu>0
\end{gathered}
$$

We have thus shown that there is a unique $u_{W}$ such that $0<u_{W}<1$ and it is given by (13).

(iia) When $x=0,(12)$ reduce to

$$
\begin{aligned}
& {\left[\delta+\mu m+\lambda m\left(1-u_{W}\right)\right] u_{B S}-\delta=0} \\
& {\left[\delta+\mu m+\lambda m\left(1-u_{W}\right)\right] u_{B C}-\delta=0}
\end{aligned}
$$

By solving these equations we obtain

$$
u_{B S}=u_{B C}=\frac{\delta}{\delta+\mu m+\lambda m\left(1-u_{W}\right)}>0
$$

It is obvious that $u_{B C}=u_{B S}$ is less than 1 since $\delta<\delta+\mu m+\lambda m\left(1-u_{W}\right)$.

We have thus shown that, when $x=0$, there is a unique $u_{B S}=u_{B C}$ such that $0<u_{B S}=u_{B C}<1$ and it is given by (14).

(iib) When $x=1,(12)$ reduce to

$$
\lambda m u_{B S}^{2}-[\delta+(\mu+\lambda) m] u_{B S}+\delta=0
$$




$$
\lambda m u_{B C}^{2}-[\delta+(\mu+\lambda) m] u_{B C}+\delta=0
$$

The discriminant for each equation is the same and given by $\Delta_{B S}=\Delta_{B C}=$ $[\delta+(\mu+\lambda) m]^{2}-4 \lambda m \delta$. It is easy to verify that if $\mu>\lambda$, then $\Delta_{B S}>0$. We thus have two distinct roots that are given by

$$
u_{B S}=u_{B C}=\frac{\delta+(\mu+\lambda) m \pm \sqrt{[\delta+(\mu+\lambda) m]^{2}-4 \lambda m \delta}}{2 \lambda m}
$$

and both of them are strictly positive. Let us show that the root with the highest value is strictly greater than 1 . This is equivalent to

$$
\delta+(\mu+\lambda) m+\sqrt{[\delta+(\mu+\lambda) m]^{2}-4 \lambda m \delta}>2 \lambda m
$$

which is always true as soon as $\mu>\lambda$. Let us show that the root with the lowest value is strictly less than 1 . This is equivalent to

$$
\delta+(\mu+\lambda) m-\sqrt{[\delta+(\mu+\lambda) m]^{2}-4 \lambda m \delta}<2 \lambda m
$$

or

$$
\begin{gathered}
(\delta+\mu m-\lambda m)^{2}<[\delta+(\mu+\lambda) m]^{2}-4 \lambda m \delta \\
\Leftrightarrow \mu \lambda m+\delta \mu>0
\end{gathered}
$$

We have thus shown that, when $x=1$, there is a unique $u_{B S}=u_{B C}$ such that $0<u_{B S}=u_{B C}<1$ and it is given by $(15)$.

(iic) When $0<x<1$, (12) reduce to

$$
\begin{aligned}
& \lambda m x u_{B S}^{2}-\left[\delta+\mu m+\lambda m\left(1-(1-x) u_{W}\right)\right] u_{B S}+\delta=0 \\
& \lambda m x u_{B C}^{2}-\left[\delta+\mu m+\lambda m\left(1-(1-x) u_{W}\right)\right] u_{B C}+\delta=0
\end{aligned}
$$

The discriminant of both of these equations is given by:

$$
\Delta=\left[\delta+\mu m+\lambda m\left[1-(1-x) u_{W}\right]\right]^{2}-4 \delta \lambda m x
$$

Let us check that it is positive. This is equivalent to:

$$
\left[\delta+\mu m+\lambda m\left[1-(1-x) u_{W}\right]\right]^{2}>4 \delta \lambda m x
$$

or

$$
\delta^{2}+\mu^{2} m^{2}+\lambda^{2} m^{2}\left(1-u_{W}+x u_{W}\right)^{2}+2 \mu \lambda m^{2}\left(1-u_{W}+x u_{W}\right)
$$




$$
\begin{gathered}
+2 \delta \mu m+2 \delta \lambda m\left(1-u_{W}+x u_{W}\right)-4 \delta \lambda m x>0 \\
\Leftrightarrow \delta^{2}+\mu^{2} m^{2}+\lambda^{2} m^{2}\left(1-u_{W}+x u_{W}\right)^{2}+2 \mu \lambda m^{2}\left(1-u_{W}+x u_{W}\right) \\
+2 \delta m(\mu-\lambda x)+2 \delta \lambda m\left(1-u_{W}\right)(1-x)>0
\end{gathered}
$$

This last inequality is always true for $x<1$ if $\mu>\lambda$. Thus $\Delta>0$. As a result, we have two distinct roots that are given by:

$$
u_{B S}(x)=u_{B C}(x)=\frac{\delta+\mu m+\lambda m\left[1-(1-x) u_{W}\right] \pm \sqrt{\Delta}}{2 \lambda m x}
$$

and both of them are strictly positive. Let us show that the root with the highest value is strictly greater than 1 . This is equivalent to

$$
\delta+\mu m+\lambda m\left[1-(1-x) u_{W}\right]+\sqrt{\Delta}>2 \lambda m x
$$

or

$$
\delta+m(\mu-\lambda x)+\lambda m(1-x)\left(1-u_{W}\right)+\sqrt{\Delta}>0
$$

which is always true for $x<1$ if $\mu>\lambda$. Let us now show that the root with the lowest value is strictly less than 1 . We have:

$$
\delta+\mu m+\lambda m\left[1-(1-x) u_{W}\right]-\sqrt{\Delta}<2 \lambda m x
$$

which, using the value of $\Delta$, is equivalent to (taking the square on both sides):

$$
\lambda m x-\delta+\sqrt{\Delta}>0
$$

Two cases may arise. If $\lambda m x \geq \delta$, then this inequality is always satisfied. Consider the case when $\delta>\lambda m x$. Then, taking again the square on both sides give:

$$
\begin{gathered}
\lambda^{2} m^{2}\left(1-u_{W}+x u_{W}\right)^{2}+2 \mu \lambda m^{2}\left(1-u_{W}+x u_{W}\right)+2 \delta \mu m \\
+m^{2}(\mu-\lambda x)(\mu+\lambda x)+2 \delta \lambda m\left(1-u_{W}+x u_{W}\right)-4 \delta \lambda m x>0
\end{gathered}
$$

This last inequality is again always true for $x<1$ if $\mu>\lambda$.

We have thus shown that, when $0<x<1$, there is a unique $u_{B S}(x)=u_{B C}(x)$ such that $0<u_{B S}(x)=u_{B C}(x)<1$ and it is given by (16).

\section{Proof of Proposition 1}

Before proving this proposition, we need the following three Lemmata. 
Lemma 3 Assume $\mu>\lambda$. The functions $u_{B S}(x)$ and $u_{B C}(x)$ are both strictly increasing with $x$ on the interval $[u(0), u(1)]$, where $0<u(0)<1$ and $0<u(1)<1$ are respectively defined by (14) and (15). More precisely, for $i=B S, B C$, we have:

$$
\frac{\partial u_{i}(x)}{\partial x} \equiv u_{i}^{\prime}(x)=\frac{\lambda m u_{i}(x)\left(u_{i}(x)-u_{W}\right)}{\delta+\mu m+\lambda m\left(1-u_{W}+x u_{W}\right)-2 \lambda m x u_{i}(x)}>0
$$

Proof. By totally differentiating (18) and (19), we respectively obtain (20) for $i=B S, B C$. Furthermore, using Lemma 1, both numerators are clearly strictly positive. Finally, the denominator of (20) can be rewritten as

$$
\begin{gathered}
\delta+m\left(\mu-\lambda x u_{i}\right)+\lambda m\left(1-u_{W}+x u_{W}-x u_{i}\right) \\
=\delta+m\left(\mu-\lambda x u_{i}\right)+\lambda m\left[1-u_{i}+\left(u_{i}-u_{W}\right)(1-x)\right]
\end{gathered}
$$

Since $\mu>\lambda$, and $x$ and $u_{i}$ are both less than 1 , then $m\left(\mu-\lambda x u_{i}\right)>0$. Using Lemma 1 and the fact that both $x$ and $u_{i}$ are less than 1 , then $1-u_{i}+\left(u_{i}-u_{W}\right)(1-x)>0$. As a result, the denominator is strictly positive and $\partial u_{i}(x) / \partial x>0$ for $k=B S, B C$.

Lemma 4 Assume $\mu>\lambda$. For $k=B S, B C$, the function $u_{i}^{\prime}(x)$ is strictly increasing on the interval $\left[u^{\prime}(0), u^{\prime}(1)\right]$, where $u^{\prime}(0)$ and $u^{\prime}(1)$ have both finite values and are respectively given by

$$
\begin{gathered}
u^{\prime}(0) \equiv u_{B S}^{\prime}(0)=u_{B C}^{\prime}(0)=\frac{\lambda m u(0)\left(u(0)-u_{W}\right)}{\delta+\mu m+\lambda m\left(1-u_{W}\right)}>0 \\
u^{\prime}(1) \equiv u_{B S}^{\prime}(1)=u_{B C}^{\prime}(1)=\frac{\lambda m u(1)\left(u(1)-u_{W}\right)}{\delta+\mu m+\lambda m(1-2 u(1))}>0
\end{gathered}
$$

where $u_{W}, u(0)$ and $u(1)$ are respectively defined by (13), (14) and (15).

Proof. By totally differentiating (18) and (19) twice, for $i=B S, B C$, we obtain:

$$
\frac{\partial^{2} u_{i}(x)}{\partial x^{2}} \equiv u_{i}^{\prime \prime}(x)=\frac{2 \lambda m u_{i}^{\prime}(x)\left(2 u_{i}(x)-u_{W}+x u_{i}^{\prime}(x)\right)}{\delta+\mu m+\lambda m\left(1-u_{W}+x u_{W}\right)-2 \lambda m x u_{i}(x)}
$$

which is clearly strictly positive. This shows that $u_{i}^{\prime}(x)$ is strictly increasing. To calculate the values of $u^{\prime}(0)$ and $u^{\prime}(1)$, it remains to respectively plug the value $x=0$ and $x=1$ in (20) and we easily obtain (21) and (22). Finally, let us show that $u^{\prime}(0)$ and $u^{\prime}(1)$ have both finite values. Since $u^{\prime}(0)<u^{\prime}(1)$, it suffices to show that $u^{\prime}(1)$ is bounded above. In fact, it is easy to see that $u^{\prime}(1)<1 /(1-u(1))$. Indeed, this rewrites

$$
\frac{\lambda m u(1)\left(u(1)-u_{W}\right)}{\delta+m(\mu-\lambda u(1))+\lambda m(1-u(1))}<\frac{1}{1-u(1)}
$$


or equivalently

$$
\lambda m\left[u(1)\left(u(1)-u_{W}\right)-1\right]<\frac{\delta+m(\mu-\lambda u(1))}{1-u(1)}
$$

This inequality is always true for $\mu>\lambda$. Indeed, we know from Lemma 1 that $u(1)>u_{W}$ and from Lemma 2 that $0<u_{W}<1$ and $0<u(1)<1$ so that the left hand side of this inequality is negative $\left(u(1)\left(u(1)-u_{W}\right)<1\right)$ and the right hand side is positive since $\mu>\lambda>\lambda u(1)$. We have thus shown that

$$
u^{\prime}(1)<\frac{1}{1-u(1)}
$$

Now, since from Lemma 2 we know that $0<u(1)<1$, this implies that $1 /(1-u(1))$ has a finite value and thus both $u^{\prime}(0)$ and $u^{\prime}(1)$ have finite values.

Lemma 5 For $i=B S, B C$, the expected utility function $E V_{i}(x)$ is strictly concave on $[0,1]$.

Proof. The expected utility function $E V_{B S}(x)$ and $E V_{B C}(x)$ are respectively given by:

$$
\begin{aligned}
E V_{B S}(x) & =\left(1-u_{B S}(x)\right)\left(y_{E}-e_{B S} x\right)+u_{B S}(x)\left(y_{U}-e_{B S} x\right) \\
& =y_{E}-e_{B S} x-u_{B S}(x)\left(y_{E}-y_{U}\right)
\end{aligned}
$$

and

$$
\begin{aligned}
E V_{B C}(x) & =\left(1-u_{B C}(x)\right)\left(y_{E}+e_{B C} x\right)+u_{B C}(x)\left(y_{U}+e_{B C} x\right) \\
& =y_{E}+e_{B C} x-u_{B C}(x)\left(y_{E}-y_{U}\right)
\end{aligned}
$$

By differentiating twice each function, we easily obtain:

$$
\begin{aligned}
& \frac{\partial^{2} E V_{B S}(x)}{\partial x^{2}}=-u_{B S}^{\prime \prime}(x)\left(y_{E}-y_{U}\right)<0 \\
& \frac{\partial^{2} E V_{B C}(x)}{\partial x^{2}}=-u_{B C}^{\prime \prime}(x)\left(y_{E}-y_{U}\right)<0
\end{aligned}
$$

Both are strictly negative since, in Lemma 4, we have shown that $u_{B S}^{\prime \prime}(x)$ and $u_{B C}^{\prime \prime}(x)$, defined by $(23)$, are strictly positive.

Let us now prove Proposition 1. 
(i) The first order condition for status-seekers is given by:

$$
\frac{\partial E V_{B S}(x)}{\partial x}=-e_{B S}-u_{B S}^{\prime}(x)\left(y_{E}-y_{U}\right)<0
$$

This is strictly negative since, in Lemma 3 , we have shown that $u_{B S}^{\prime}(x)>0$. As a result, status-seekers will find always optimal to choose $x_{B S}^{*}=0$.

(ii) The first order condition for conformists is given by:

$$
\frac{\partial E V_{B C}(x)}{\partial x}=e_{B C}-u_{B C}^{\prime}(x)\left(y_{E}-y_{U}\right)=0
$$

Since $e_{B C}>0$ and $-u_{B C}^{\prime}(x)\left(y_{E}-y_{U}\right)>0$, different cases may arise. We know however from Lemma 4 that $u_{B C}^{\prime}(x)$ is strictly increasing on the interval $\left[u^{\prime}(0), u^{\prime}(1)\right]$, where $u^{\prime}(0)$ and $u^{\prime}(1)$ are both strictly positive and have finite values, and from Lemma 5 that $E V_{B C}(x)$ is strictly concave on $[0,1]$. Then, it should be clear that we have the following results:

(iia) If $e_{B C} /\left(y_{E}-y_{U}\right) \leq u^{\prime}(0)$, this implies that $e_{B C} /\left(y_{E}-y_{U}\right) \leq u_{B C}^{\prime}(x)$, $\forall x \in[0,1]$, and thus $\partial E V_{B C}(x) / \partial x<0$. As a result, the optimal choice is $x_{B C}^{*}=0$ and the unemployment rate of conformists and status-seekers are identical, $u_{B S}(0)=$ $u_{B C}(0)$, and given by (14). Inspection of (10) shows that the probability to find a job are also the same and equal to

$$
m \theta_{B S}(0)=m \theta_{B C}(0)=\mu m+\lambda m\left(1-u_{W}\right)
$$

(iib) If $u^{\prime}(0)<e_{B C} /\left(y_{E}-y_{U}\right)<u^{\prime}(1)$, then $E V_{B C}(x)$ is increasing up to $e_{B C} /\left(y_{E}-y_{U}\right)$ and then decreases. As a result, the maximum of $E V_{B C}(x)$ is reached between $x=0$ and $x=1$ so that the solution is always interior, i.e. $0<x_{B C}^{*}<1$. This implies that the unemployment rate of conformists is always higher than that of status-seekers since, using Lemma $3, u(0)$ defined by (14) is always strictly less than $u_{B C}(x)$ defined by (16). Thus, using Lemma 1 , it should be clear that the probability to find a job is lower for a conformist than for a status-seeker since, $\forall x \in] 0,1[$,

$$
m \theta_{B S}(0)=\mu m+\lambda m\left(1-u_{W}\right)<m \theta_{B C}(x)=\mu m+\lambda m\left[1-u_{W}-x\left(u_{B C}-u_{W}\right)\right]
$$

(iic) If $e_{B C} /\left(y_{E}-y_{U}\right) \geq u^{\prime}(1)$, this implies that $e_{B C} /\left(y_{E}-y_{U}\right) \geq u_{B C}^{\prime}(x)$, $\forall x \in[0,1]$, and thus $\partial E V_{B C}(x) / \partial x>0$. As a result, the optimal choice is $x_{B C}^{*}=1$. This implies that the unemployment rate of conformists is always higher than that of status-seekers since, using Lemma $3, u(0)$ defined by (14) is always strictly less than $u(1)$ defined by (15). As a result, we have

$$
m \theta_{B S}(0)=\mu m+\lambda m\left(1-u_{W}\right)<m \theta_{B C}(1)=\mu m+\lambda m x\left(1-u_{B C}\right)
$$

i.e. a status-seeker has a higher probability to find a job than a conformist. 
Table 1: Means and standard deviations of selected variables

\begin{tabular}{|c|c|c|c|}
\hline Variable & Mean & $\begin{array}{l}\text { Std. } \\
\text { Dev. }\end{array}$ & Description \\
\hline Empilo & 0.776 & 0.417 & $\begin{array}{l}\text { Employment status, } 1 \text { if employed } 0 \text { otherwise (ILO } \\
\text { definition) }\end{array}$ \\
\hline Employed & 0.647 & 0.478 & 1 if is an employee \\
\hline Oethcon & 0.053 & 0.223 & 1 if living in own ethnic concentration of $33 \%$ or more \\
\hline Owncar & 0.754 & 0.431 & 1 if owns a car \\
\hline $\begin{array}{l}\text { Owner- } \\
\text { occupier }\end{array}$ & 0.720 & 0.449 & 1 if owner occupier \\
\hline Caribbean & 0.296 & 0.457 & 1 if of Caribbean origin \\
\hline Indian & 0.278 & 0.428 & 1 if of Indian origin \\
\hline African-Asian & 0.159 & 0.365 & 1 if of African-Asian origin \\
\hline Pakistani & 0.165 & 0.373 & 1 if of Pakistan origin \\
\hline Bangladeshi & 0.056 & 0.229 & 1 if of Bangladesh origin \\
\hline Chinese & 0.046 & 0.265 & 1 if of Chinese origin \\
\hline Ukdeg & 0.118 & 0.323 & 1 if has UK higher degree, degree, Diploma or equivalent \\
\hline Ukalev & 0.149 & 0.406 & 1 if has UK A-Level qualification or equivalent \\
\hline Ukolev & 0.255 & 0.498 & 1 if has UK O-Level qualification or equivalent \\
\hline Nukqual & 0.478 & 0.500 & 1 if has no UK qualification \\
\hline Fqual & 0.206 & 0.404 & 1 if has any foreign qualifications \\
\hline Fdeg & 0.066 & 0.249 & $\begin{array}{l}1 \text { if has foreign higher degree, degree, Diploma or } \\
\text { equivalent }\end{array}$ \\
\hline Falevel & 0.042 & 0.200 & 1 if has Foreign A-Level qualification or equivalent \\
\hline Folevel & 0.090 & 0.286 & 1 if has foreign 0-Level qualification or equivalent \\
\hline Nfogual & 0.802 & 0.398 & 1 if has no foreign qualification \\
\hline Fluent & 0.726 & 0.446 & 1 if speaks English fluently \\
\hline Age & 33.89 & 11.93 & Age of respondent \\
\hline Married & 0.714 & 0.452 & 1 if married or living together \\
\hline Arrmar & 0.164 & 0.371 & 1 if had arranged marriage \\
\hline Child04 & 0.407 & 0.491 & Presence of children of age less than 5 \\
\hline Childd511 & 0.508 & 0.500 & Presence of children between 5 and 11 years old \\
\hline Child 1215 & 0.328 & 0.469 & Presence of children between 12 and 15 years old \\
\hline Child16ov & 0.370 & 0.483 & Presence of children of 16 years or more \\
\hline Male & 0.600 & 0.490 & 1 if male \\
\hline Yrsmg & 21.01 & 9.44 & Years since migration \\
\hline UKborn & 0.332 & 0.471 & 1 if born in the UK \\
\hline Rharra & 0.131 & 0.338 & 1 if was racially harassed \\
\hline Schrelig & 0.167 & 0.373 & 1 if prefers own religion school for children \\
\hline
\end{tabular}


Table 2: In many ways I think of myself as British (\% )

\begin{tabular}{lrrrrrr}
\hline & Caribbean & Indian & $\begin{array}{r}\text { African } \\
\text { Asian }\end{array}$ & Pakistani & Bangladeshi & Chinese \\
\hline Strongly agree & 20.09 & 13.98 & 25.79 & 22.53 & 14.23 & 10.00 \\
Agree & 37.77 & 43.69 & 45.28 & 37.55 & 41.90 & 38.00 \\
Neither & 8.30 & 13.40 & 10.69 & 16.21 & 20.55 & 11.00 \\
Disagree & 24.02 & 23.30 & 16.04 & 15.22 & 18.58 & 33.00 \\
Strongly & 9.83 & 5.63 & 2.20 & 8.50 & 4.74 & 8.00 \\
disagree & & & & & & \\
$\mathbf{N}$ & $\mathbf{4 5 8}$ & $\mathbf{5 1 5}$ & $\mathbf{3 1 8}$ & $\mathbf{5 0 6}$ & $\mathbf{2 5 3}$ & $\mathbf{1 0 0}$ \\
\hline
\end{tabular}

Table 3: In many ways I think of myself as ....[Respondent's ethnic group] (\% )

\begin{tabular}{lrrrrrr}
\hline & Caribbean & Indian & $\begin{array}{r}\text { African } \\
\text { Asian }\end{array}$ & Pakistani & Bangladeshi & Chinese \\
\hline Strongly agree & 49.89 & 39.81 & 43.71 & 44.36 & 49.61 & 53.00 \\
Agree & 34.06 & 47.57 & 42.14 & 41.78 & 44.09 & 40.00 \\
Neither & 6.50 & 7.18 & 8.80 & 9.70 & 2.75 & 1.00 \\
Disagree & 7.59 & 4.85 & 4.72 & 2.57 & 3.15 & 4.00 \\
Strongly disagree & 1.95 & 0.58 & 0.63 & 1.58 & 0.39 & 2.00 \\
$\mathbf{N}$ & $\mathbf{4 6 1}$ & $\mathbf{5 1 5}$ & $\mathbf{3 1 8}$ & $\mathbf{5 0 5}$ & $\mathbf{2 5 4}$ & $\mathbf{1 0 0}$ \\
\hline
\end{tabular}

Table 4: If a close relative were to marry a white person (\%)

\begin{tabular}{lrrrrrr}
\hline & Caribbean & Indian & $\begin{array}{r}\text { African } \\
\text { Asian }\end{array}$ & Pakistani & Bangladeshi & Chinese \\
\hline Would not mind & 82.43 & 51.87 & 66.25 & 38.61 & 49.60 & 84.69 \\
Mind a little & 6.51 & 10.02 & 11.04 & 11.09 & 9.20 & 6.12 \\
Mind very much & 8.24 & 27.89 & 13.56 & 36.83 & 33.20 & 7.14 \\
Can't say & 2.82 & 10.22 & 9.15 & 13.47 & 8.00 & 2.05 \\
$\mathbf{N}$ & $\mathbf{4 6 1}$ & $\mathbf{5 0 9}$ & $\mathbf{3 1 7}$ & $\mathbf{5 0 5}$ & $\mathbf{2 5 0}$ & $\mathbf{9 8}$ \\
\hline
\end{tabular}

Table 5: How important is ethnicity in choosing a school? (\% )

\begin{tabular}{lrrrrrr}
\hline & Caribbean & Indian & $\begin{array}{r}\text { African } \\
\text { Asian }\end{array}$ & Pakistani & Bangladeshi & Chinese \\
\hline Very important & 15.94 & 6.81 & 8.44 & 12.06 & 16.21 & 3.03 \\
Fairly important & 20.74 & 16.15 & 15.31 & 16.60 & 18.58 & 7.07 \\
Not very important & 16.16 & 13.42 & 10.31 & 15.02 & 16.21 & 15.15 \\
No influence & 44.32 & 57.78 & 59.06 & 47.23 & 38.34 & 73.74 \\
Can't say & 2.84 & 5.84 & 6.88 & 9.09 & 10.67 & 1.01 \\
$\mathbf{N}$ & $\mathbf{4 5 8}$ & $\mathbf{5 1 4}$ & $\mathbf{3 2 0}$ & $\mathbf{5 0 6}$ & $\mathbf{2 5 3}$ & $\mathbf{9 9}$ \\
\hline
\end{tabular}

Table 6: What proportion of one's ethnic group would you like in your children's school? (\%)

\begin{tabular}{lrrrrrr}
\hline & Caribbean & Indian & $\begin{array}{r}\text { African } \\
\text { Asian }\end{array}$ & Pakistani & Bangladeshi & Chinese \\
\hline Fewer than half & 16.67 & 11.07 & 14.42 & 9.49 & 14.17 & 23.23 \\
About half & 35.06 & 18.83 & 20.06 & 28.06 & 30.31 & 7.07 \\
More than half & 4.11 & 1.55 & 1.57 & 5.14 & 5.12 & 1.01 \\
No preference & 40.69 & 63.11 & 56.11 & 48.62 & 40.94 & 68.69 \\
Can't say & 3.46 & 5.44 & 7.84 & 8.70 & 9.45 & 0.00 \\
$\mathbf{N}$ & $\mathbf{4 6 2}$ & $\mathbf{5 1 5}$ & $\mathbf{3 1 9}$ & $\mathbf{5 0 6}$ & $\mathbf{2 5 4}$ & $\mathbf{9 9}$ \\
\hline
\end{tabular}


Table 7: Oppositional identity variables

\begin{tabular}{|c|c|c|c|}
\hline Variable & Description & Mean & Std. Dev. \\
\hline Nbrit & $\begin{array}{l}1 \text { if strongly disagree that in many ways I think of } \\
\text { myself as British, } 0 \text { if neither agree or disagree, } \\
\text { agree, disagree, strongly agree and can't say. }\end{array}$ & 0.067 & 0.250 \\
\hline Oethnic & $\begin{array}{l}1 \text { if strongly agree that in many ways I think of } \\
\text { myself as being of the original ethnic group (e.g. } \\
\text { Indian, Pakistani etc), } 0 \text { if neither agree nor } \\
\text { disagree, agree, disagree, strongly disagree and } \\
\text { can't say. }\end{array}$ & 0.456 & 0.498 \\
\hline Smind & $\begin{array}{l}1 \text { if mind very much if a relative marries a white } \\
\text { person, } 0 \text { if does not mind, mind very little and } \\
\text { can't say. }\end{array}$ & 0.190 & 0.392 \\
\hline Schch & $\begin{array}{l}1 \text { if the number of children from own ethnic group } \\
\text { would have a very important influence in school } \\
\text { choice for an } 11 \text { year old child, } 0 \text { if fairly important, } \\
\text { not very important, no influence and can't say. }\end{array}$ & 0.114 & 0.318 \\
\hline Opid & $\begin{array}{l}1 \text { if extremely oppositional (at least two of nbrit, } \\
\text { oethnic, smind or schch equal to one), } 0 \text { otherwise }\end{array}$ & 0.0867 & 0.2815 \\
\hline
\end{tabular}


Table 8: Non-white conformists -probit regressions

\begin{tabular}{|c|c|c|c|c|c|}
\hline & Smind & Schcon & Nbrit & Oethnic & Opid \\
\hline \multirow[t]{2}{*}{ age } & -0.010 & -0.007 & -0.000 & 0.013 & -0.011 \\
\hline & $(0.76)$ & $(0.54)$ & $(0.08)$ & $(0.93)$ & $(1.65)+$ \\
\hline \multirow[t]{2}{*}{ age2 } & 0.015 & 0.005 & 0.002 & -0.009 & 0.014 \\
\hline & (1.05) & $(0.36)$ & $(0.27)$ & $(0.53)$ & $(1.76)+$ \\
\hline \multirow[t]{2}{*}{ male } & -0.021 & 0.025 & -0.017 & -0.027 & -0.012 \\
\hline & $(0.63)$ & $(0.78)$ & $(1.43)$ & $(0.73)$ & $(0.61)$ \\
\hline \multirow[t]{2}{*}{ marown } & -0.075 & -0.006 & -0.010 & -0.054 & -0.020 \\
\hline & (1.41) & $(0.11)$ & $(0.58)$ & $(0.94)$ & $(0.70)$ \\
\hline \multirow[t]{2}{*}{ Intmar } & -0.253 & -0.097 & -0.036 & -0.067 & -0.084 \\
\hline & $(3.63)^{* *}$ & $(1.30)$ & $(1.79)+$ & $(0.76)$ & $(2.31)^{*}$ \\
\hline \multirow[t]{2}{*}{ child04 } & 0.018 & 0.037 & -0.022 & 0.005 & -0.027 \\
\hline & $(0.51)$ & (1.05) & $(1.56)$ & $(0.13)$ & $(1.37)$ \\
\hline \multirow[t]{2}{*}{ chid511 } & 0.060 & 0.004 & 0.011 & -0.042 & 0.029 \\
\hline & $(1.90)+$ & $(0.13)$ & $(0.88)$ & (1.17) & $(1.68)+$ \\
\hline \multirow[t]{2}{*}{$\operatorname{ch} 1215$} & 0.009 & 0.030 & 0.001 & -0.037 & 0.026 \\
\hline & $(0.27)$ & (0.89) & $(0.12)$ & $(0.97)$ & (1.34) \\
\hline \multirow[t]{2}{*}{ Oethcon } & 0.039 & 0.014 & 0.041 & 0.128 & 0.027 \\
\hline & $(0.87)$ & $(0.30)$ & $(2.44)^{*}$ & $(2.36)^{*}$ & (1.11) \\
\hline \multirow[t]{2}{*}{ Caribbean } & -0.224 & 0.177 & 0.098 & 0.061 & 0.001 \\
\hline & $(4.60) * *$ & $(2.98)^{* *}$ & $(2.70)^{* *}$ & $(0.98)$ & $(0.02)$ \\
\hline \multirow[t]{2}{*}{ African-Asian } & -0.145 & 0.060 & -0.044 & -0.094 & -0.049 \\
\hline & $(3.33) * *$ & (1.15) & $(2.02) *$ & $(1.78)+$ & $(1.97)^{*}$ \\
\hline \multirow[t]{2}{*}{ Bangladeshi/Pakistani } & -0.074 & 0.102 & -0.004 & -0.000 & 0.003 \\
\hline & $(1.96)+$ & $(2.49) *$ & $(0.33)$ & $(0.01)$ & $(0.16)$ \\
\hline \multirow[t]{2}{*}{ Ukdeg } & -0.097 & 0.160 & -0.017 & -0.079 & 0.004 \\
\hline & (1.48) & $(2.42)^{*}$ & $(0.92)$ & (1.17) & $(0.10)$ \\
\hline Ukalev & 0.164 & 0.016 & -0.031 & -0.019 & 0.011 \\
\hline & $(2.45)^{*}$ & $(0.26)$ & $(1.71)+$ & $(0.30)$ & $(0.28)$ \\
\hline Ukolev & -0.001 & 0.027 & -0.025 & 0.023 & -0.032 \\
\hline & $(0.02)$ & $(0.56)$ & (1.54) & $(0.41)$ & (1.19) \\
\hline Fqual & -0.061 & -0.024 & 0.008 & -0.115 & -0.026 \\
\hline & $(1.80)+$ & $(0.67)$ & $(0.59)$ & $(2.92)^{* *}$ & $(1.45)$ \\
\hline Fluent & -0.093 & -0.009 & -0.026 & -0.135 & -0.027 \\
\hline & $(2.20)^{*}$ & $(0.22)$ & $(1.82)+$ & $(2.92)^{* *}$ & $(1.98)^{*}$ \\
\hline Northyh & 0.092 & 0.013 & 0.030 & 0.195 & 0.060 \\
\hline & $(2.02) *$ & $(0.29)$ & $(1.60)$ & $(3.94) * *$ & $(2.13)^{*}$ \\
\hline Midland & 0.034 & 0.042 & 0.027 & 0.048 & 0.036 \\
\hline & $(0.95)$ & $(1.20)$ & $(1.85)+$ & (1.21) & (1.69)+ \\
\hline owneroccu & 0.005 & -0.081 & -0.036 & -0.048 & -0.030 \\
\hline & $(0.12)$ & $(2.26)^{*}$ & $(2.52)^{*}$ & (1.14) & (1.48) \\
\hline owncar & -0.003 & -0.060 & 0.020 & 0.052 & -0.006 \\
\hline & $(0.08)$ & $(1.69)+$ & $(1.72)+$ & $(1.22)$ & $(0.28)$ \\
\hline une59 & 0.182 & -0.011 & 0.008 & -0.168 & 0.011 \\
\hline & $(2.26) *$ & $(0.10)$ & $(0.18)$ & (1.63) & $(0.14)$ \\
\hline un1014 & 0.113 & 0.134 & 0.061 & 0.100 & 0.057 \\
\hline & (1.30) & (1.19) & $(1.20)$ & $(0.95)$ & $(0.66)$ \\
\hline un1519 & 0.108 & 0.037 & 0.033 & 0.184 & 0.012 \\
\hline & $(1.22)$ & $(0.33)$ & $(0.66)$ & $(1.73)+$ & $(0.17)$ \\
\hline une20m & 0.161 & 0.122 & 0.034 & 0.137 & 0.007 \\
\hline & $(1.78)+$ & (1.09) & $(0.75)$ & (1.28) & $(0.10)$ \\
\hline ukborn & -0.084 & -0.103 & -0.048 & -0.355 & -0.084 \\
\hline & (1.16) & (1.57) & $(3.30) * *$ & $(4.80) * *$ & $(3.30)^{* *}$ \\
\hline ysmg & -0.012 & -0.021 & -0.003 & -0.007 & -0.003 \\
\hline & $(0.09)$ & $(0.67)$ & $(4.02)^{* *}$ & $(2.72)^{* *}$ & $(2.21)^{*}$ \\
\hline rharra & 0.122 & 0.060 & 0.046 & 0.006 & 0.056 \\
\hline & $(2.46)^{*}$ & $(1.76)+$ & $(2.37)^{*}$ & $(0.12)$ & $(1.81)+$ \\
\hline schrelig & 0.217 & 0.116 & 0.031 & 0.142 & 0.115 \\
\hline & $(5.74) * *$ & $(3.22) * *$ & $(2.28) *$ & $(3.50) * *$ & $(5.28) * *$ \\
\hline arrmar & 0.155 & 0.046 & $\begin{array}{c}0.045 \\
(2.93) * *\end{array}$ & 0.004 & 0.052 \\
\hline Observations & 1057 & 1055 & 942 & 1056 & 991 \\
\hline Pseudo $R^{2}$ & 0.1940 & 0.1665 & 0.2044 & 0.1609 & 0.1818 \\
\hline Unrestricted Log likelihood $(\varphi)$ & -521.01 & -578.69 & -206.27 & -686.60 & -280.94 \\
\hline Wald $\chi^{2}(\mathrm{~m})$ & 212.20 & 93.50 & 88.66 & 80.42 & 114.44 \\
\hline Prob $>\chi^{2}$ & 0.0000 & 0.0000 & 0.0000 & 0.0000 & 0.0000 \\
\hline Restricted Log likelihood $(\theta)$ & -630.55 & -685.84 & -272.15 & -815.04 & -357.62 \\
\hline LR test $\chi^{2}(3)$ & 219.08 & 214.30 & 131.76 & 256.88 & 153.36 \\
\hline
\end{tabular}


Table 9: Employment - probit regressions (correcting for endogeneity)

\begin{tabular}{|c|c|c|c|c|c|}
\hline & (1) & $(2)$ & (3) & (4) & (5) \\
\hline age & $\begin{array}{c}0.055 \\
(3.45)^{* *}\end{array}$ & $\begin{array}{c}0.050 \\
(3.03)^{* *}\end{array}$ & $\begin{array}{c}0.066 \\
(3.79) * *\end{array}$ & $\begin{array}{c}0.058 \\
(3.41)^{* *}\end{array}$ & $\begin{array}{c}0.052 \\
(3.30)^{* *}\end{array}$ \\
\hline age2 & $\begin{array}{c}-0.062 \\
(3.33)^{* *}\end{array}$ & $\begin{array}{c}-0.060 \\
(3.10) * *\end{array}$ & $\begin{array}{c}-0.074 \\
(3.70) * *\end{array}$ & $\begin{array}{c}-0.065 \\
(3.25)^{* *}\end{array}$ & $\begin{array}{c}-0.060 \\
(3.20)^{* *}\end{array}$ \\
\hline male & $\begin{array}{l}-0.060 \\
(1.01)\end{array}$ & $\begin{array}{l}-0.064 \\
(0.75)\end{array}$ & $\begin{array}{l}-0.071 \\
(1.14)\end{array}$ & $\begin{array}{l}-0.063 \\
(0.52)\end{array}$ & $\begin{array}{l}-0.059 \\
(1.00)\end{array}$ \\
\hline marown & $\begin{array}{c}0.147 \\
(1.94)+\end{array}$ & $\begin{array}{c}0.136 \\
(1.76)+\end{array}$ & $\begin{array}{l}0.109 \\
(1.14)\end{array}$ & $\begin{array}{l}0.129 \\
(0.96)\end{array}$ & $\begin{array}{c}0.130 \\
(1.72)+\end{array}$ \\
\hline intmar & $\begin{array}{c}0.197 \\
(1.91)+\end{array}$ & $\begin{array}{c}0.196 \\
(1.79)+\end{array}$ & $\begin{array}{c}0.170 \\
(1.43)\end{array}$ & $\begin{array}{l}0.183 \\
(1.50)\end{array}$ & $\begin{array}{c}0.201 \\
(2.01)^{*}\end{array}$ \\
\hline child04 & $\begin{array}{l}0.034 \\
(0.72)\end{array}$ & $\begin{array}{c}0.034 \\
(0.69)\end{array}$ & $\begin{array}{l}-0.000 \\
(0.01)\end{array}$ & $\begin{array}{l}0.022 \\
(0.43)\end{array}$ & $\begin{array}{l}0.012 \\
(0.27)\end{array}$ \\
\hline chid511 & $\begin{array}{c}-0.090 \\
(2.05)^{*}\end{array}$ & $\begin{array}{c}-0.116 \\
(2.75)^{* *}\end{array}$ & $\begin{array}{c}-0.099 \\
(2.20)^{*}\end{array}$ & $\begin{array}{c}-0.112 \\
(2.75)^{* *}\end{array}$ & $\begin{array}{c}-0.098 \\
(2.31)^{*}\end{array}$ \\
\hline ch1215 & $\begin{array}{c}-0.092 \\
(2.03)^{*}\end{array}$ & $\begin{array}{c}-0.098 \\
(1.61)\end{array}$ & $\begin{array}{l}-0.107 \\
(2.25)^{*}\end{array}$ & $\begin{array}{c}-0.104 \\
(2.14)^{*}\end{array}$ & $\begin{array}{l}-0.089 \\
(1.98)^{*}\end{array}$ \\
\hline oethcon & $\begin{array}{l}-0.072 \\
(1.12)\end{array}$ & $\begin{array}{l}-0.059 \\
(0.92)\end{array}$ & $\begin{array}{c}-0.050 \\
(1.90)+\end{array}$ & $\begin{array}{l}-0.059 \\
(1.57)\end{array}$ & $\begin{array}{l}-0.076 \\
(1.19)\end{array}$ \\
\hline Caribbean & $\begin{array}{c}-0.061 \\
(1.90)+\end{array}$ & $\begin{array}{l}-0.052 \\
(0.36)\end{array}$ & $\begin{array}{l}-0.051 \\
(0.24)\end{array}$ & $\begin{array}{l}-0.053 \\
(0.34)\end{array}$ & $\begin{array}{l}-0.053 \\
(1.31)\end{array}$ \\
\hline African-Asian & $\begin{array}{l}0.006 \\
(0.07)\end{array}$ & $\begin{array}{l}0.082 \\
(1.14)\end{array}$ & $\begin{array}{l}0.010 \\
(0.12)\end{array}$ & $\begin{array}{l}0.045 \\
(0.56)\end{array}$ & $\begin{array}{l}0.038 \\
(0.51)\end{array}$ \\
\hline Bangladeshi/Pakistani & $\begin{array}{c}-0.251 \\
(5.33)^{* *}\end{array}$ & $\begin{array}{c}-0.236 \\
(3.87)^{* *}\end{array}$ & $\begin{array}{c}-0.254 \\
(4.33)^{* *}\end{array}$ & $\begin{array}{c}-0.266 \\
(4.47)^{* *}\end{array}$ & $\begin{array}{c}-0.254 \\
(4.62)^{* *}\end{array}$ \\
\hline ukdeg & $\begin{array}{c}0.234 \\
(2.90)^{* *}\end{array}$ & $\begin{array}{c}0.253 \\
(3.24)^{* *}\end{array}$ & $\begin{array}{c}0.225 \\
(2.67)^{* *}\end{array}$ & $\begin{array}{c}0.221 \\
(2.44)^{*}\end{array}$ & $\begin{array}{c}0.238 \\
(3.05)^{* *}\end{array}$ \\
\hline ukalev & $\begin{array}{c}0.109 \\
(1.37)\end{array}$ & $\begin{array}{l}0.110 \\
(1.38)\end{array}$ & $\begin{array}{c}0.097 \\
(0.90)\end{array}$ & $\begin{array}{c}0.090 \\
(1.05)\end{array}$ & $\begin{array}{l}0.097 \\
(1.23)\end{array}$ \\
\hline ukolev & $\begin{array}{l}0.026 \\
(0.40)\end{array}$ & $\begin{array}{l}0.040 \\
(0.62)\end{array}$ & $\begin{array}{l}0.042 \\
(0.51)\end{array}$ & $\begin{array}{l}0.029 \\
(0.42)\end{array}$ & $\begin{array}{l}0.029 \\
(0.29)\end{array}$ \\
\hline fqual & $\begin{array}{l}0.015 \\
(0.30)\end{array}$ & $\begin{array}{c}0.018 \\
(0.37)\end{array}$ & $\begin{array}{c}0.038 \\
(0.77)\end{array}$ & $\begin{array}{l}0.002 \\
(0.04)\end{array}$ & $\begin{array}{l}0.020 \\
(0.42)\end{array}$ \\
\hline fluent & $\begin{array}{c}0.077 \\
(2.42)^{*}\end{array}$ & $\begin{array}{c}0.079 \\
(2.40)^{*}\end{array}$ & $\begin{array}{c}0.084 \\
(1.67)+\end{array}$ & $\begin{array}{c}0.081 \\
(1.86)+\end{array}$ & $\begin{array}{c}0.084 \\
(2.39)^{*}\end{array}$ \\
\hline northyh & $\begin{array}{c}0.119 \\
(2.75)^{* *}\end{array}$ & $\begin{array}{c}0.113 \\
(2.18)^{*}\end{array}$ & $\begin{array}{c}0.111 \\
(2.60)^{* *}\end{array}$ & $\begin{array}{c}0.114 \\
(2.16)^{*}\end{array}$ & $\begin{array}{c}0.117 \\
(2.69)^{* *}\end{array}$ \\
\hline midland & $\begin{array}{c}0.117 \\
(2.58)^{* *}\end{array}$ & $\begin{array}{c}0.114 \\
(2.53)^{*}\end{array}$ & $\begin{array}{c}0.117 \\
(2.80)^{* *}\end{array}$ & $\begin{array}{c}0.114 \\
(2.43)^{*}\end{array}$ & $\begin{array}{c}0.126 \\
(2.73)^{* *}\end{array}$ \\
\hline ownerocu & $\begin{array}{c}0.125 \\
(2.36)^{*}\end{array}$ & $\begin{array}{c}0.141 \\
(3.24)^{* *}\end{array}$ & $\begin{array}{c}0.128 \\
(2.41)^{*}\end{array}$ & $\begin{array}{c}0.139 \\
(3.07)^{* *}\end{array}$ & $\begin{array}{c}0.122 \\
(2.51)^{*}\end{array}$ \\
\hline owncar & $\begin{array}{c}0.087 \\
(1.84)+\end{array}$ & $\begin{array}{c}0.094 \\
(1.97)^{*}\end{array}$ & $\begin{array}{c}0.088 \\
(1.77)+\end{array}$ & $\begin{array}{l}0.081 \\
(1.53)\end{array}$ & $\begin{array}{l}0.079 \\
(1.61)\end{array}$ \\
\hline Une59 & $\begin{array}{l}-0.057 \\
(0.34)\end{array}$ & $\begin{array}{l}-0.052 \\
(0.74)\end{array}$ & $\begin{array}{l}-0.055 \\
(0.74)\end{array}$ & $\begin{array}{l}-0.049 \\
(0.22)\end{array}$ & $\begin{array}{l}-0.058 \\
(0.69)\end{array}$ \\
\hline un1014 & $\begin{array}{l}-0.048 \\
(0.28)\end{array}$ & $\begin{array}{l}-0.031 \\
(0.18)\end{array}$ & $\begin{array}{l}-0.041 \\
(0.23)\end{array}$ & $\begin{array}{l}-0.052 \\
(0.29)\end{array}$ & $\begin{array}{l}-0.016 \\
(0.10)\end{array}$ \\
\hline un1519 & $\begin{array}{l}-0.047 \\
(0.10)\end{array}$ & $\begin{array}{l}-0.055 \\
(0.46)\end{array}$ & $\begin{array}{l}-0.059 \\
(0.34)\end{array}$ & $\begin{array}{l}-0.042 \\
(0.12)\end{array}$ & $\begin{array}{l}-0.045 \\
(0.27)\end{array}$ \\
\hline Une20m & $\begin{array}{l}-0.114 \\
(0.66)\end{array}$ & $\begin{array}{l}-0.097 \\
(0.04)\end{array}$ & $\begin{array}{l}-0.096 \\
(0.20)\end{array}$ & $\begin{array}{c}-0.118 \\
(0.64)\end{array}$ & $\begin{array}{l}-0.099 \\
(0.30)\end{array}$ \\
\hline ukborn & $\begin{array}{c}-0.245 \\
(2.17)^{*}\end{array}$ & $\begin{array}{c}-0.237 \\
(2.04)^{*}\end{array}$ & $\begin{array}{c}-0.228 \\
(2.44)^{*}\end{array}$ & $\begin{array}{c}-0.234 \\
(1.92)+\end{array}$ & $\begin{array}{c}-0.223 \\
(2.29)^{*}\end{array}$ \\
\hline ysmg & $\begin{array}{c}0.007 \\
(2.40)^{*}\end{array}$ & $\begin{array}{c}0.007 \\
(2.33)^{*}\end{array}$ & $\begin{array}{c}0.012 \\
(2.73)^{* *}\end{array}$ & $\begin{array}{c}0.009 \\
(2.31)^{*}\end{array}$ & $\begin{array}{c}0.009 \\
(2.64)^{* *}\end{array}$ \\
\hline smind & $\begin{array}{c}-0.064 \\
(2.02)^{*}\end{array}$ & & & & \\
\hline schcon & & $\begin{array}{l}-0.049 \\
(1.36)\end{array}$ & & & \\
\hline nbrit & & & $\begin{array}{c}-0.070 \\
(1.89)+\end{array}$ & & \\
\hline oethnic & & & & $\begin{array}{l}-0.065 \\
(1.26)\end{array}$ & \\
\hline opid & & & & & $\begin{array}{c}-0.058 \\
(1.99)^{*}\end{array}$ \\
\hline Observations & 706 & 704 & 705 & 706 & 703 \\
\hline Pseudo $\mathrm{R}^{2}$ & 0.2110 & 0.2065 & 0.2103 & 0.2083 & 0.2074 \\
\hline Log likelihood & -348.62 & -349.40 & -348.03 & -349.83 & -348.11 \\
\hline Wald $\chi^{2}(\mathrm{~m})$ & 186.51 & 181.89 & 185.39 & 184.08 & 182.18 \\
\hline Prob $>\chi^{2}$ & 0.0000 & 0.0000 & 0.0000 & 0.0000 & 0.0000 \\
\hline
\end{tabular}

Absolute value of $z$-statistics in parentheses, + significant at $10 \%$; significant at $5 \%$; ${ }^{* *}$ significant at $1 \%$. 
Table 10: Employment- probit regressions (not correcting for endogeneity)

\begin{tabular}{|c|c|c|c|c|c|}
\hline & (1) & $(2)$ & (3) & $(4)$ & $(5)$ \\
\hline age & $\begin{array}{c}0.052 \\
(3.75)^{* *}\end{array}$ & $\begin{array}{c}0.051 \\
(3.63)^{* *}\end{array}$ & $\begin{array}{c}0.053 \\
(3.83) * *\end{array}$ & $\begin{array}{c}0.052 \\
(3.76)^{* *}\end{array}$ & $\begin{array}{c}0.052 \\
(3.74)^{* *}\end{array}$ \\
\hline age2 & $\begin{array}{c}-0.059 \\
(3.56)^{* *}\end{array}$ & $\begin{array}{c}-0.058 \\
(3.48)^{* *}\end{array}$ & $\begin{array}{c}-0.061 \\
(3.65) * *\end{array}$ & $\begin{array}{c}-0.060 \\
(3.58) * *\end{array}$ & $\begin{array}{c}-0.059 \\
(3.55)^{* *}\end{array}$ \\
\hline male & $\begin{array}{l}-0.052 \\
(1.05)\end{array}$ & $\begin{array}{l}-0.053 \\
(1.08)\end{array}$ & $\begin{array}{l}-0.051 \\
(1.05)\end{array}$ & $\begin{array}{l}-0.049 \\
(0.88)\end{array}$ & $\begin{array}{l}-0.047 \\
(0.95)\end{array}$ \\
\hline marown & $\begin{array}{c}0.175 \\
(2.60)^{* *}\end{array}$ & $\begin{array}{c}0.173 \\
(2.57)^{*}\end{array}$ & $\begin{array}{c}0.168 \\
(2.52)^{*}\end{array}$ & $\begin{array}{c}0.173 \\
(2.59)^{* *}\end{array}$ & $\begin{array}{c}0.164 \\
(2.44)^{*}\end{array}$ \\
\hline intmar & $\begin{array}{c}0.210 \\
(2.86)^{* *}\end{array}$ & $\begin{array}{c}0.212 \\
(2.95)^{* *}\end{array}$ & $\begin{array}{c}0.207 \\
(2.81)^{* *}\end{array}$ & $\begin{array}{c}0.205 \\
(2.74)^{* *}\end{array}$ & $\begin{array}{c}0.198 \\
(2.63)^{* *}\end{array}$ \\
\hline child04 & $\begin{array}{l}-0.004 \\
(0.01)\end{array}$ & $\begin{array}{l}-0.004 \\
(0.02)\end{array}$ & $\begin{array}{l}-0.005 \\
(0.11)\end{array}$ & $\begin{array}{l}-0.004 \\
(0.02)\end{array}$ & $\begin{array}{l}-0.004 \\
(0.03)\end{array}$ \\
\hline chid511 & $\begin{array}{c}-0.093 \\
(2.50)^{*}\end{array}$ & $\begin{array}{c}-0.095 \\
(2.55)^{*}\end{array}$ & $\begin{array}{c}-0.093 \\
(2.50)^{*}\end{array}$ & $\begin{array}{c}-0.097 \\
(2.59)^{* *}\end{array}$ & $\begin{array}{c}-0.092 \\
(2.46)^{*}\end{array}$ \\
\hline ch1215 & $\begin{array}{l}-0.088 \\
(2.18)^{*}\end{array}$ & $\begin{array}{c}-0.083 \\
(2.04)^{*}\end{array}$ & $\begin{array}{c}-0.087 \\
(2.14) *\end{array}$ & $\begin{array}{c}-0.081 \\
(2.26)^{*}\end{array}$ & $\begin{array}{c}-0.086 \\
(2.11)^{*}\end{array}$ \\
\hline oethcon & $\begin{array}{l}-0.073 \\
(1.39)\end{array}$ & $\begin{array}{l}-0.067 \\
(1.26)\end{array}$ & $\begin{array}{l}-0.083 \\
(1.57)\end{array}$ & $\begin{array}{l}-0.073 \\
(1.39)\end{array}$ & $\begin{array}{l}-0.072 \\
(1.35)\end{array}$ \\
\hline Caribbean & $\begin{array}{l}-0.072 \\
(1.54)\end{array}$ & $\begin{array}{l}-0.075 \\
(1.14)\end{array}$ & $\begin{array}{l}-0.080 \\
(1.23)\end{array}$ & $\begin{array}{l}-0.081 \\
(1.34)\end{array}$ & $\begin{array}{l}-0.081 \\
(1.32)\end{array}$ \\
\hline African-Asian & $\begin{array}{c}0.064 \\
(1.01)\end{array}$ & $\begin{array}{l}0.066 \\
(1.24)\end{array}$ & $\begin{array}{l}0.065 \\
(1.04)\end{array}$ & $\begin{array}{c}0.073 \\
(1.18)\end{array}$ & $\begin{array}{l}0.066 \\
(1.05)\end{array}$ \\
\hline Bangladeshi/Pakistani & $\begin{array}{c}-0.242 \\
(5.04)^{* *}\end{array}$ & $\begin{array}{c}-0.233 \\
(4.85)^{* *}\end{array}$ & $\begin{array}{c}-0.238 \\
(5.00) * *\end{array}$ & $\begin{array}{c}-0.245 \\
(5.11)^{* *}\end{array}$ & $\begin{array}{c}-0.237 \\
(4.93) * *\end{array}$ \\
\hline Ukdeg & $\begin{array}{c}0.249 \\
(3.91)^{* *}\end{array}$ & $\begin{array}{c}0.250 \\
(3.86) * *\end{array}$ & $\begin{array}{c}0.247 \\
(3.80) * *\end{array}$ & $\begin{array}{c}0.249 \\
(3.87)^{* *}\end{array}$ & $\begin{array}{c}0.248 \\
(3.81)^{* *}\end{array}$ \\
\hline Ukalev & $\begin{array}{l}0.068 \\
(1.00)\end{array}$ & $\begin{array}{l}0.069 \\
(1.01)\end{array}$ & $\begin{array}{l}0.061 \\
(0.89)\end{array}$ & $\begin{array}{l}0.065 \\
(0.96)\end{array}$ & $\begin{array}{l}0.066 \\
(0.97)\end{array}$ \\
\hline Ukolev & $\begin{array}{c}0.082 \\
(1.47)\end{array}$ & $\begin{array}{l}0.082 \\
(1.45)\end{array}$ & $\begin{array}{l}0.075 \\
(1.32)\end{array}$ & $\begin{array}{c}0.079 \\
(1.39)\end{array}$ & $\begin{array}{c}0.076 \\
(1.35)\end{array}$ \\
\hline Fqual & $\begin{array}{c}0.049 \\
(1.16)\end{array}$ & $\begin{array}{l}0.048 \\
(1.13)\end{array}$ & $\begin{array}{c}0.053 \\
(1.28)\end{array}$ & $\begin{array}{c}0.053 \\
(1.27)\end{array}$ & $\begin{array}{l}0.048 \\
(1.14)\end{array}$ \\
\hline Fluent & $\begin{array}{c}0.091 \\
(1.84)+\end{array}$ & $\begin{array}{c}0.096 \\
(1.97)^{*}\end{array}$ & $\begin{array}{c}0.097 \\
(1.99)^{*}\end{array}$ & $\begin{array}{c}0.092 \\
(2.01)^{*}\end{array}$ & $\begin{array}{c}0.091 \\
(1.96)+\end{array}$ \\
\hline Northyh & $\begin{array}{c}0.110 \\
(2.43)^{*}\end{array}$ & $\begin{array}{c}0.104 \\
(2.28)^{*}\end{array}$ & $\begin{array}{c}0.107 \\
(2.34)^{*}\end{array}$ & $\begin{array}{c}0.108 \\
(2.33)^{*}\end{array}$ & $\begin{array}{c}0.109 \\
(2.40) *\end{array}$ \\
\hline Midland & $\begin{array}{c}0.122 \\
(3.17)^{* *}\end{array}$ & $\begin{array}{c}0.122 \\
(3.19)^{* *}\end{array}$ & $\begin{array}{c}0.124 \\
(3.21)^{* *}\end{array}$ & $\begin{array}{c}0.121 \\
(3.15)^{* *}\end{array}$ & $\begin{array}{c}0.123 \\
(3.20)^{* *}\end{array}$ \\
\hline Ownerocu & $\begin{array}{c}0.167 \\
(4.54)^{* *}\end{array}$ & $\begin{array}{c}0.154 \\
(3.94)^{* *}\end{array}$ & $\begin{array}{c}0.164 \\
(3.89) * *\end{array}$ & $\begin{array}{c}0.161 \\
(3.14)^{* *}\end{array}$ & $\begin{array}{c}0.171 \\
(3.47)^{*}\end{array}$ \\
\hline owncar & $\begin{array}{c}0.114 \\
(1.72)+\end{array}$ & $\begin{array}{c}0.123 \\
(1.83)+\end{array}$ & $\begin{array}{c}0.118 \\
(2.07)^{*}\end{array}$ & $\begin{array}{l}0.109 \\
(1.62)\end{array}$ & $\begin{array}{c}0.127 \\
(1.89)+\end{array}$ \\
\hline une59 & $\begin{array}{l}-0.106 \\
(0.77)\end{array}$ & $\begin{array}{r}-0.112 \\
(0.81)\end{array}$ & $\begin{array}{l}-0.114 \\
(0.83)\end{array}$ & $\begin{array}{l}-0.103 \\
(0.74)\end{array}$ & $\begin{array}{l}-0.114 \\
(0.83)\end{array}$ \\
\hline un1014 & $\begin{array}{l}-0.064 \\
(0.43)\end{array}$ & $\begin{array}{l}-0.048 \\
(0.33)\end{array}$ & $\begin{array}{l}-0.054 \\
(0.37)\end{array}$ & $\begin{array}{l}-0.070 \\
(0.50)\end{array}$ & $\begin{array}{l}-0.056 \\
(0.38)\end{array}$ \\
\hline un1519 & $\begin{array}{l}0.008 \\
(0.05)\end{array}$ & $\begin{array}{l}0.015 \\
(0.10)\end{array}$ & $\begin{array}{c}0.017 \\
(0.12)\end{array}$ & $\begin{array}{l}0.003 \\
(0.02)\end{array}$ & $\begin{array}{c}0.012 \\
(0.08)\end{array}$ \\
\hline une20m & $\begin{array}{l}-0.091 \\
(0.62)\end{array}$ & $\begin{array}{l}-0.072 \\
(0.49)\end{array}$ & $\begin{array}{l}-0.084 \\
(0.57)\end{array}$ & $\begin{array}{l}-0.093 \\
(0.63)\end{array}$ & $\begin{array}{l}-0.084 \\
(0.58)\end{array}$ \\
\hline ukborn & $\begin{array}{c}-0.232 \\
(2.41)^{*}\end{array}$ & $\begin{array}{c}-0.234 \\
(2.43)^{*}\end{array}$ & $\begin{array}{c}-0.238 \\
(2.46)^{*}\end{array}$ & $\begin{array}{c}-0.226 \\
(2.35)^{*}\end{array}$ & $\begin{array}{c}-0.237 \\
(2.44)^{*}\end{array}$ \\
\hline ysmg & $\begin{array}{l}-0.007 \\
(2.45)^{*}\end{array}$ & $\begin{array}{c}-0.007 \\
(2.47)^{*}\end{array}$ & $\begin{array}{c}-0.007 \\
(2.59)^{* *}\end{array}$ & $\begin{array}{l}-0.007 \\
(2.39)^{*}\end{array}$ & $\begin{array}{c}-0.007 \\
(2.54)^{*}\end{array}$ \\
\hline smind & $\begin{array}{l}-0.050 \\
(1.27)\end{array}$ & & & & \\
\hline schcon & & $\begin{array}{c}-0.079 \\
(2.18)^{*}\end{array}$ & & & \\
\hline nbrit & & & $\begin{array}{c}-0.113 \\
(1.82)+\end{array}$ & & \\
\hline oethnic & & & & $\begin{array}{l}-0.008 \\
(0.25)\end{array}$ & \\
\hline opid & & & & & $\begin{array}{c}-0.090 \\
(1.66)+\end{array}$ \\
\hline Observations & 828 & 827 & 826 & 827 & 823 \\
\hline Pseudo $\mathrm{R}^{2}$ & 0.2127 & 0.2137 & 0.2134 & 0.2119 & 0.2120 \\
\hline Log likelihood & -406.85 & 405.42 & -404.68 & -407.01 & -403.91 \\
\hline Wald $\chi^{2}(\mathrm{~m})$ & 168.64 & 170.86 & 167.39 & 169.98 & 164.98 \\
\hline Prob $>\chi^{2}$ & 0.0000 & 0.0000 & 0.0000 & 0.0000 & 0.0000 \\
\hline
\end{tabular}

Robust z-statistics in parentheses, + significant at $10 \%$; ${ }^{*}$ significant at $5 \%$; ** significant at $1 \%$. 


\section{IZA Discussion Papers}

\begin{tabular}{|c|c|c|c|c|}
\hline No. & Author(s) & Title & Area & Date \\
\hline 706 & $\begin{array}{l}\text { S. Girma } \\
\text { H. Görg }\end{array}$ & $\begin{array}{l}\text { Blessing or Curse? Domestic Plants' Survival } \\
\text { and Employment Prospects after Foreign } \\
\text { Acquisitions }\end{array}$ & 1 & $01 / 03$ \\
\hline 707 & $\begin{array}{l}\text { C. Schnabel } \\
\text { J. Wagner }\end{array}$ & $\begin{array}{l}\text { Trade Union Membership in Eastern and } \\
\text { Western Germany: Convergence or } \\
\text { Divergence? }\end{array}$ & 3 & $01 / 03$ \\
\hline 708 & $\begin{array}{l}\text { C. Schnabel } \\
\text { J. Wagner }\end{array}$ & $\begin{array}{l}\text { Determinants of Trade Union Membership in } \\
\text { Western Germany: Evidence from Micro Data, } \\
\text { 1980-2000 }\end{array}$ & 3 & $01 / 03$ \\
\hline 709 & $\begin{array}{l}\text { L. Danziger } \\
\text { S. Neuman }\end{array}$ & $\begin{array}{l}\text { Delays in Renewal of Labor Contracts: Theory } \\
\text { and Evidence }\end{array}$ & 1 & $02 / 03$ \\
\hline 710 & $\begin{array}{l}\text { Z. Eckstein } \\
\text { Y. Weiss }\end{array}$ & $\begin{array}{l}\text { On the Wage Growth of Immigrants: Israel, } \\
1990-2000\end{array}$ & 2 & $02 / 03$ \\
\hline 711 & C. Ruhm & Healthy Living in Hard Times & 3 & $02 / 03$ \\
\hline 712 & $\begin{array}{l}\text { E. Fehr } \\
\text { J. Henrich }\end{array}$ & $\begin{array}{l}\text { Is Strong Reciprocity a Maladaptation? On the } \\
\text { Evolutionary Foundations of Human Altruism }\end{array}$ & 5 & $02 / 03$ \\
\hline 713 & $\begin{array}{l}\text { I. Gang } \\
\text { J. Landon-Lane } \\
\text { M. S. Yun }\end{array}$ & $\begin{array}{l}\text { Does the Glass Ceiling Exist? A Cross-National } \\
\text { Perspective on Gender Income Mobility }\end{array}$ & 2 & $02 / 03$ \\
\hline 714 & M. Fertig & $\begin{array}{l}\text { Educational Production, Endogenous Peer } \\
\text { Group Formation and Class Composition - } \\
\text { Evidence From the PISA } 2000 \text { Study }\end{array}$ & 6 & $02 / 03$ \\
\hline 715 & $\begin{array}{l}\text { E. Fehr } \\
\text { U. Fischbacher } \\
\text { B. von Rosenbladt } \\
\text { J. Schupp } \\
\text { G. G. Wagner }\end{array}$ & $\begin{array}{l}\text { A Nation-Wide Laboratory Examining Trust and } \\
\text { Trustworthiness by Integrating Behavioral } \\
\text { Experiments into Representative Surveys }\end{array}$ & 7 & $02 / 03$ \\
\hline 716 & $\begin{array}{l}\text { M. Rosholm } \\
\text { L. Skipper }\end{array}$ & $\begin{array}{l}\text { Is Labour Market Training a Curse for the } \\
\text { Unemployed? Evidence from a Social } \\
\text { Experiment }\end{array}$ & 6 & $02 / 03$ \\
\hline 717 & $\begin{array}{l}\text { A. Hijzen } \\
\text { H. Görg } \\
\text { R. C. Hine }\end{array}$ & $\begin{array}{l}\text { International Fragmentation and Relative Wages } \\
\text { in the UK }\end{array}$ & 2 & $02 / 03$ \\
\hline 718 & E. Schlicht & Consistency in Organization & 1 & $02 / 03$ \\
\hline 719 & $\begin{array}{l}\text { J. Albrecht } \\
\text { P. Gautier } \\
\text { S. Vroman }\end{array}$ & $\begin{array}{l}\text { Equilibrium Directed Search with Multiple } \\
\text { Applications }\end{array}$ & 3 & $02 / 03$ \\
\hline 720 & T. Palokangas & $\begin{array}{l}\text { Labour Market Regulation, Productivity- } \\
\text { Improving R\&D and Endogenous Growth }\end{array}$ & 3 & $02 / 03$ \\
\hline 721 & $\begin{array}{l}\text { H. Battu } \\
\text { M. Mwale } \\
\text { Y. Zenou }\end{array}$ & $\begin{array}{l}\text { Do Oppositional Identities Reduce Employment } \\
\text { for Ethnic Minorities? }\end{array}$ & 1 & $02 / 03$ \\
\hline
\end{tabular}

An updated list of IZA Discussion Papers is available on the center's homepage www.iza.org. 